\title{
1 Economic opportunities and trade-offs in collaborative forest landscape restoration
}

\section{2}

3

4

5

6

$7{ }^{\mathrm{c}}$ Oregon State University, College of Forestry, Forest Ecosystems \&Society, 321 Richardson Hall,

8 Corvallis, OR 97331 USA, email: michelle.day@oregonstate.edu

\section{Abstract}

10 We modeled forest restoration scenarios to examine economic and ecological trade-offs

11 associated with alternative prioritization scenarios. The study examined four US national forests

12 designated as priorities for investments to restore fire resiliency and generate economic

13 opportunities to support local industry. We were particularly interested in trade-offs between

14 generating revenue from forest restoration activities versus addressing ecological departure from

15 fire resiliency, and wildfire risk to the urban interface. The results showed strong trade-offs and

16 scale effects on production possibility frontiers, and substantial variation among planning areas

17 and national forests. The results pointed to spatially explicit priorities and opportunities to

18 achieve restoration goals within the study area. However, optimizing revenue to help finance

19 restoration projects led to a sharp reduction in the attainment of other socioecological objectives,

20 especially reducing ecological departure from historic conditions. The analytical framework and

21 results can inform ongoing collaborative restoration planning programs to help stakeholders 
22 understand the opportunity cost of specific restoration objectives. This work represents the first

23 spatially explicit, economic trade-off analysis of national forest restoration programs, and reveals

24 the relative cost of different restoration strategies, as well scale-related changes in production

25 frontiers associated with restoration investments.

26 Keywords: forest restoration, spatial optimization, restoration prioritization, production

27 possibility frontiers, collaborative planning

\section{1. Introduction}

29 Restoration ecology has increasingly become a key component of many land management 30 programs on both public and private lands in many regions of the world (Adame et al., 2015;

31 BenDor et al., 2015; Wilson et al., 2012). A case in point are the large scale forest restoration

32 programs initiated on western US national forests under the Healthy Forest Restoration Act

33 (HFRA, 2003) to improve the health and fire resiliency of the dry forest ecosystem (Noss et al.,

34 2006; USDA Forest Service, 2012). The program encompasses a multitude of ecosystems and

35 services with focal points on resiliency of landscapes to fire, watershed condition, invasive

36 species, and wildlife habitat. Fire resiliency objectives are achieved through fuel management

37 projects that use forest thinning, prescribed fire, and a range of other techniques aimed at

38 returning fire frequent forests to pre-settlement conditions (Agee and Skinner, 2005; Brown et

39 al., 2004). The program was broadened with the Forest Landscape Restoration Act (Omnibus

40 Public Land Management Act of 2009, Title IV) to establish a network of collaboratives to guide

41 science-based planning efforts and promote diverse restoration approaches to meet broad

42 ecological, economic, and resource protection objectives (Butler et al., 2015). Key outputs from

43 the restoration program include commercial wood supply to private entities to offset restoration

44 treatment costs and increased employment in rural economies (USDA Forest Service, 2016b). 
45 The science dialog around the program has been extensive, and included discussions of

46 ecological goals (Brown et al., 2004; Haugo et al., 2015; Moore et al., 1999; Noss et al., 2006),

47 planning frameworks (Butler et al., 2015; Franklin and Johnson, 2012; Schultz et al., 2012;

48 USDA Forest Service, 2016b), implementation strategies (Rieman et al., 2010), economic

49 assessments (Rasmussen et al., 2012; Rummer, 2008), and human dimensions (Franklin et al.,

50 2014; Payne, 2013). A recent five-year review of the Collaborative Forest Restoration Program

51 (CFLRP, USDA Forest Service, 2015a) and a national conference of managers and stakeholders

52 highlighted local implementation of the program and results from specific restoration projects.

53 Ongoing implementation of the restoration programs and inclusion of diverse stakeholder

54 groups in the planning process has increasingly challenged federal land managers to better

55 articulate priorities and desired outcomes from the program (Butler et al., 2015). Under the

56 current process, local forest managers in concert with stakeholder groups attempt to blend local

57 values with broad regional assessments of restoration needs under national policy direction

58 (Butler et al., 2015). The analytical component of current collaborative planning efforts largely

59 consists of ad hoc analysis of spatial data from regional and local assessments coupled with field

60 observations to determine site specific projects and planning areas (Butler et al., 2015).

61 Guidelines and analytical protocols to prioritize restoration planning areas based on singular or

62 multiple criteria (Neeson et al., 2016), including economics (Adame et al., 2015; Kimball et al.,

63 2015), are non-existent. Nor are analyses conducted to evaluate trade-offs among economic

64 services and the reduction of stressors (Allan et al., 2013; Bullock et al., 2011; Maron and

65 Cockfield, 2008) that potentially impact the forests.

66 Trade-offs in restoration stem from finite budgets, capacity, and spatial variation and

67 covariation across different restoration targets (Anderson et al., 2009; Martin et al., 2016; 
68 Neeson et al., 2016). Thus, the opportunity cost of emphasizing one restoration objective over

69 another is not known to stakeholders in the collaborative planning programs. Moreover, trade-

70 offs are not exposed in regional assessments of restoration need because they either generally

71 have a singular objective (Haugo et al., 2015; Rasmussen et al., 2012; USDA Forest Service,

72 2011) or the coarse scale of assessment inputs precludes analysis at the implementation scale

73 (Barbour et al., 2008e; Rasmussen et al., 2012). The net result is that spatial priorities and

74 targets established by regional assessments to address specific socioeconomic and ecological

75 issues, including wood supply (Barbour et al., 2008a), fire protection to the wildland urban

76 interface (WUI, Bailey, 2013), and ecological departure from historical conditions (Haugo et al.,

77 2015) ignore trade-offs, and may well suggest unobtainable or non-optimal outcomes due to

78 scale effects on production functions (King et al., 2015) or scale mismatches (Cumming et al.,

79 2006) between assessments and project implementation. Integrating economic and ecological

80 trade-off analyses into current programs could have manifold effects on long-term effectiveness

81 in terms of sustaining rural economies, and meeting fire resiliency objectives on large fire prone

82 landscapes. For instance, economic analyses can help maximize the scale of treatments by

83 subsiding expensive fuels, mastication, and thinning treatments of small non-commercial trees

84 with harvesting and sale of commercially viable materials elsewhere within planning areas.

85 In this paper we describe a detailed analysis of economic and ecological trade-offs within a

86 fire prone ecoregion that includes four US national forests (NF) designated as a national priority

87 for restoration (USDA Forest Service, 2016a). We first examined how generating revenue from

88 restoration affected opportunities to address social and ecological goals within 102 individual

89 planning areas among the four national forests within the ecoregion. We then examined

90 cumulative net revenue realized from specific restoration targets over increasing scales of 
91 implementation. Of specific interest was the idea that maximizing revenue could help facilitate

92 building large fire resilient landscapes by subsidizing treatment of forest stands that cannot

93 produce economic benefits, but require fuels treatment for fire resiliency objectives. We use the

94 study to stimulate a discussion about ways to improve stakeholder engagement in the

95 prioritization of restoration projects as part of a collaborative planning framework (Butler et al.,

96 2015) via the use of production frontiers (Cavender-Bares et al., 2015; King et al., 2015) (Fig. 1).

97

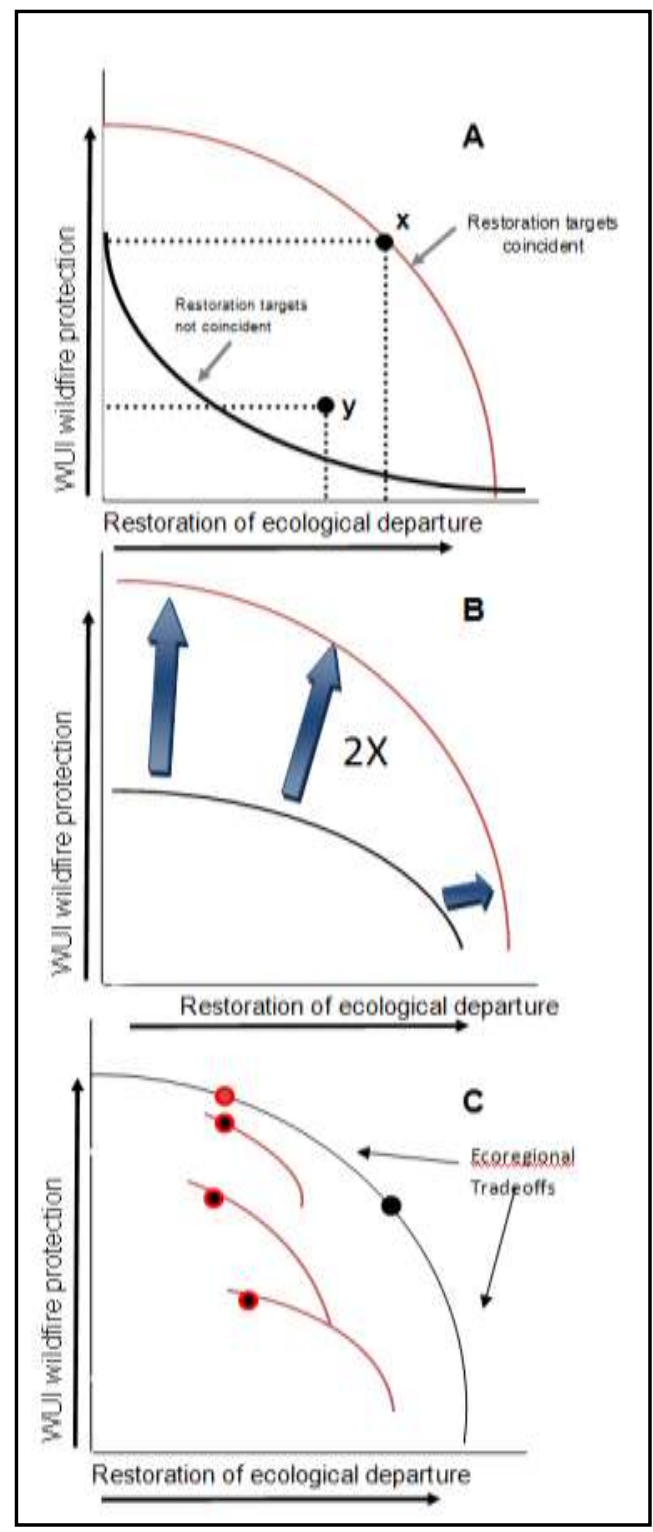


98 Fig. 1. Examples of how production possibility frontiers (PPF) can be interpreted to facilitate 99 decision trade-offs and collaborative planning in forest restoration programs. A) Convex to the

100 original (black line) versus concave to the origin (red line) production relationships caused by

101 spatial correlation, or lack thereof, of restoration targets determine the magnitude of trade-offs

102 between competing restoration objectives and the need for collaborative planning; B) effect of

103 increasing the scale from an accelerated restoration program where investment inputs are

104 doubled and the ability to achieve multiple restoration goals is constrained because of differential

105 scarcity in the restoration targets; and C) example where local collaborative groups select

106 projects for implementation within national forests (red circles) but local preferences result in a

107 non-optimal or non-preferred mix of outputs at the ecoregional scale. Panel C adapted from King 108 et al. (2015).

109 2. Methods

110 2.1. Study Area

111 The study area encompassed four national forests (Malheur, Ochoco, Umatilla and Wallowa-

112 Whitman) in the Blue Mountain ecoregion (USDA Forest Service, 1994) of eastern Oregon and

113 southeastern Washington and includes 2.5 million ha of forest and rangelands (Fig. 2). The area

114 is interspersed with small mountain ranges, canyons, and plateaus. Elevations generally range

115 from $900 \mathrm{~m}$ to $1500 \mathrm{~m}$, with higher peaks close to $3000 \mathrm{~m}$. Dry forests of ponderosa pine (Pinus

116 ponderosa Lawson \& C. Lawson) dominate lower elevations, with dry mixed conifer (grand fir

117 (Abies grandis (Douglas ex D. Don) Lindl) and Douglas-fir (Pseudotsuga menziesii (Mirb.)

118 Franco)) at higher elevations. Cold dry forested areas are dominated by lodgepole pine (Pinus 119 contorta Douglas ex Loudon) at higher elevations. About 50\% of the study area is designated for 
120 active forest management with mechanical treatments, with the remaining areas protected by

121 wilderness and roadless legislation, and conservation. The forests were heavily managed for

122 timber production until the mid-1990s. A combination of factors, including ecological and

123 amenity values, led to a severe decline in commercial harvest from about 1.85 to 0.56 million

124 cubic meters per year. Wildfires and insect outbreaks have impacted stand structure and

125 composition in some areas. About 22,000 ha (0.9\%) are burned annually by predominantly

126 lightning caused wildfires (1992-2013) (Short, 2015). Forest insect epidemics are a regular

127 occurrence (Ager et al., 2004) with current outbreaks observed for mountain pine beetle

128 (Dendroctonus ponderosae Hopkins) and western pine beetle (D. brevicomis LaConte).

129 However, over most of the area stand densification resulting from fire exclusion has resulted in 130 densification.

131 In a recent study, Hagmann et al. (2013) reported a tripling of stand densities on adjacent

132 national forests over the past 90 years (68 \pm 28 trees ha- 1 to $234 \pm 122$ trees ha- 1$)$, although the

133 proportion of large, fire resilient trees $(>53 \mathrm{~cm} \mathrm{DBH})$ decreased by more than a factor of five. At

134 the same time, Hagmann et al. (2013) reported less than a 20\% increase in mean basal area, with

135 the basal area of large trees declining by $>50 \%$, leaving large areas susceptible to future

136 disturbance from insects and wildfire. 


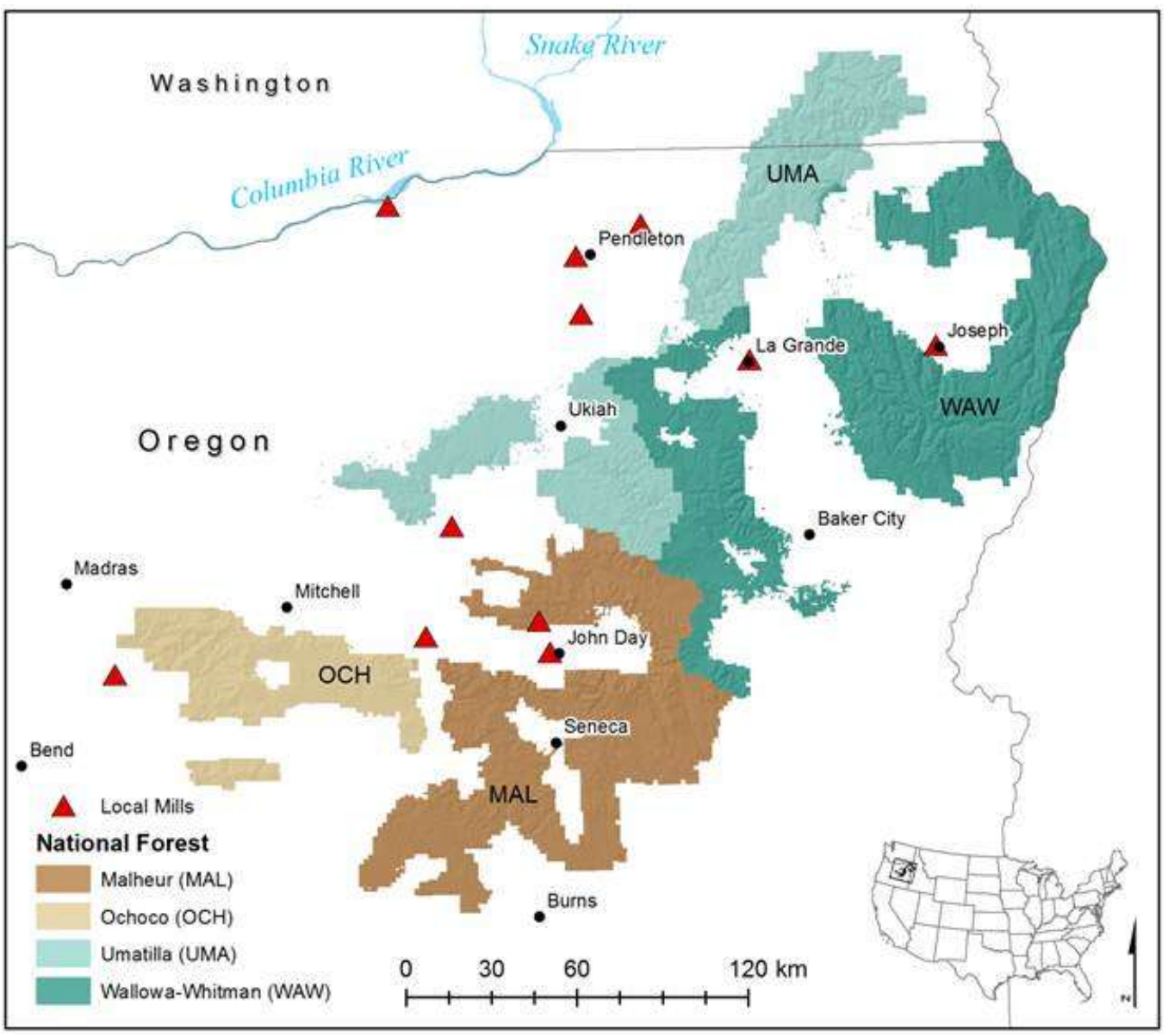

138 Fig. 2. Map of the study area showing the four national forests in the Blue Mountains ecoregion

139 of eastern Oregon and southeastern Washington, USA, and the locations of 22 wood processing

140 facilities used in the haul cost calculation. Wood processing facilities included mills that

141 consume $\operatorname{logs}$ to generate dimensional lumber. Facilities that generated specialty wood products

142 from saw logs or consumed chips for pulp or energy were not included. Figure adapted from

143 Ager et al. (2016).

144 Estimates of restoration need vary, with initial estimates suggesting that $34 \%(506,696$ ha) of

145 the forested area is in need of active restoration (USDA Forest Service, 2013). Downscaling a

146 more recent analysis of ecological departure for the Pacific Northwest (Haugo et al., 2015), we

147 estimated that roughly 890,000 ha $(58 \%)$ of the study area within managed forests (excluding 
148 wilderness and other conservation reserves) are in a state of significant ecological departure.

149 Forest restoration treatments (mechanical treatments and fire) are completed on about 32,000 ha

150 annually, or about $3.6 \%$ of the area $(2005-2015)$. Specific forest treatments mirror

151 management activities on other national forests (Agee and Skinner, 2005; Roccaforte et al.,

152 2008), where overstocked stands are thinned from below and surface fuels are treated to reduce

153 the severity of potential wildfire behavior. Large scale restoration projects within the study area

154 specify treating an average of about 5000 ha within planning areas that range in size from 20,000

155 to 40,000 ha. Mechanical thinning thresholds (i.e., the selection of stands to treat) and particular

156 thinning intensities follow guidelines by Cochran et al. (1994; see section 2.2.4).

157 2.2. Modeled Restoration Objectives

158 We used restoration objectives described in Ager et al. (2016) and further outlined in

159 Appendix A. Individual forest stands $(n=204,610)$ were defined using corporate USDA Forest

160 Service spatial databases. The stand layer was obtained from the national forests and is used for

161 project planning with stand boundaries following natural breaks in vegetation types and changes

162 in stand structure from past management activities. Each stand was attributed with a land

163 management designation from respective forest land management and resource plans, and

164 protected areas within biodiversity and amenity reserves, including wilderness and inventoried

165 roadless areas, were removed from consideration for restoration treatments. This resulted in a

166 layer that consisted of 145,395 stands ranging in size from $<1$ ha to 493 ha (mean $=10.6$ ha), and

167 totaled $1,542,226$ ha (64\% of the study area). The following restoration objectives were defined:

168 1) forest departure from historic conditions, 2) potential basal area mortality from insects and

169 disease, 3) potential wildfire hazard, 4) wildfire exposure to the wildland urban interface (WUI),

170 5) potential stemwood volume from mechanical thinning treatments, and 6) total net value of 
171 treatments. The development of each objective is described below with more detailed

172 descriptions in Appendix A and C. Finally, the study area was divided into 102 planning areas

173 (average size $=15,102$ ha) based on input from national forests (Fig. 3). The planning areas

174 generally follow subwatershed boundaries.

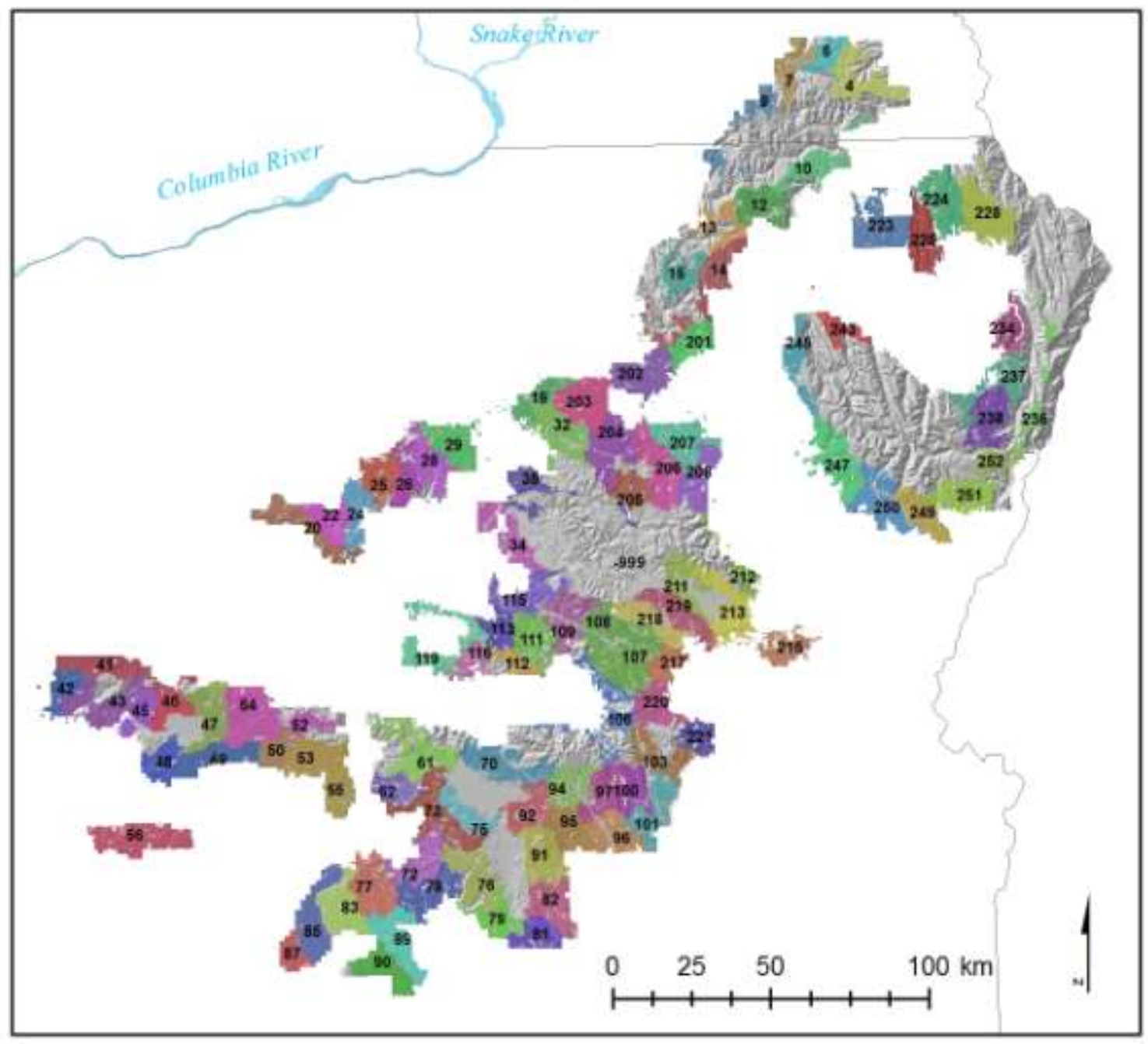

176 Fig. 3. Map of the 102 planning areas on the four national forests included in the study area.

177 Planning area boundaries generally follow watershed boundaries in the study area. Small parcels

178 created by discontinuities between national forest ownerships and watershed boundaries were

179 merged with adjacent planning areas consistent with planning area delineation used by the 180 national forests. 


\subsection{Forest Departure from Historical Reference Conditions}

182 We used spatial data on ecological departure from Haugo et al. (2015) that quantifies

183 departure of current vegetation conditions from historical vegetation conditions (Appendix A).

184 The methodology builds on LANDFIRE (2013b) and fire regime-condition class score which

185 have been widely used to prioritize stands and landscapes for treatments as specified in the

186 National Fire Plan (USDA-USDI 2001). Ecological departure in forests (hereafter forest

187 departure) can stem from both surplus and deficiencies of species, however data we used from

188 Haugo et al. (2015) measures stand densification and changes in species composition towards

189 fire intolerant species. The $30 \mathrm{~m}$ gridded data were averaged for each stand (Fig. 4A).

190 2.4. Insect and Disease Risk

191 Insect epidemics influence management objectives and restoration treatment opportunities

192 due to forest health concerns. We used spatial data from the National Insect and Disease Risk

193 Map (FHTET, 2014) to estimate basal area loss due to major insects and diseases over a15 year

194 future time period (2013-2027). The process incorporates 186 individual risk models using host

195 tree species maps and ancillary data such as climate, topography, soils, and pest occurrence. Data

196 for the assessment are generated nationally at a resolution of $240 \mathrm{~m}$. We averaged grid values for

197 average basal area loss in each stand to estimate basal area mortality from insects and disease 198 (Fig. 4B).

199 2.5. Wildfire Hazard

200 We used FlamMap (Finney, 2006), a widely used fire simulation software package, to obtain 201 an estimate of potential fire behavior for each stand assuming static weather conditions and fuel 
202 moisture (Appendix A). Surface and canopy fuels flame length data were obtained from

203 LANDFIRE (2013a) to estimate fire intensity. Fire weather parameters represented $97^{\text {th }}$

204 percentile weather conditions for the central Blue Mountains and were derived from a previous

205 study (see Table 1 in Ager et al., 2007). These methods are similar to those used on many

206 national forests to identify high fire hazard areas for fuel reduction activities. Simulations used

$20790 \mathrm{~m}$ resolution and the resulting grid of flame lengths was overlaid with the stand map to

208 calculate average fire intensity per stand (Fig. 4E).

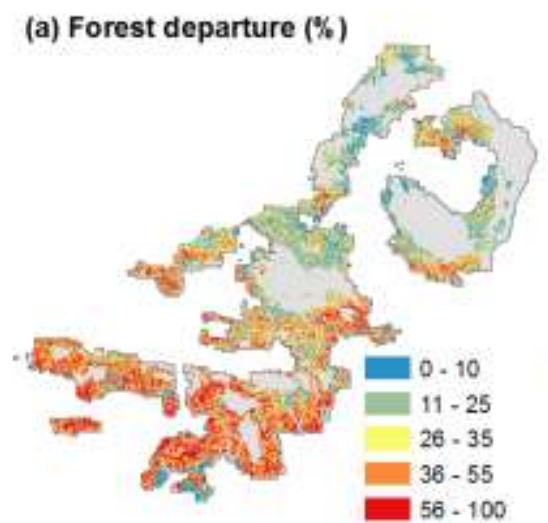

(d) Structure exposure from NF (structures year ${ }^{-1}$ )

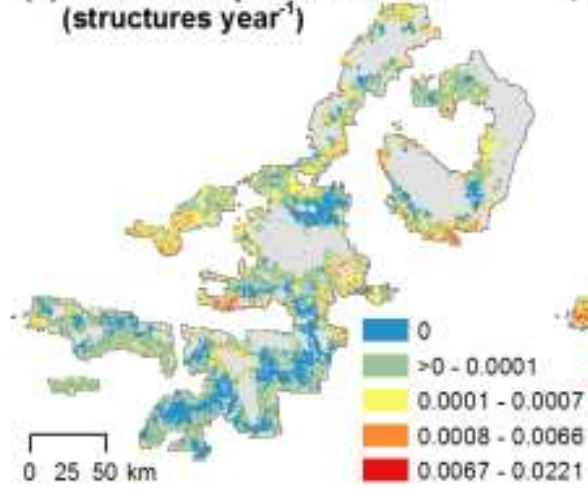

(b) Insect risk $\left(\mathrm{m}^{2} \mathrm{ha}^{-1}\right)$

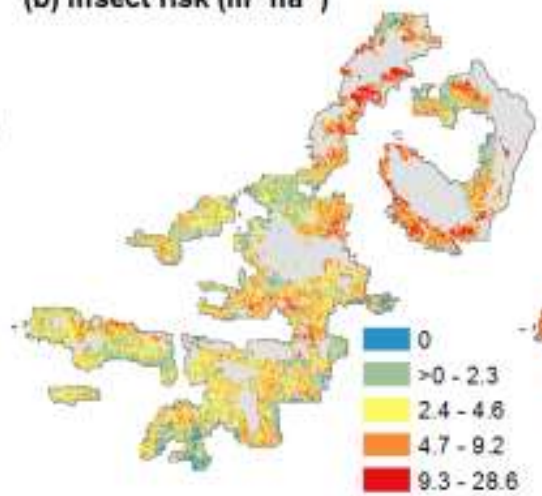

(e) Wildfire hazard (m)
(c)Thinning volume $\left(\mathrm{m}^{3} \mathrm{ha}^{-4}\right)$

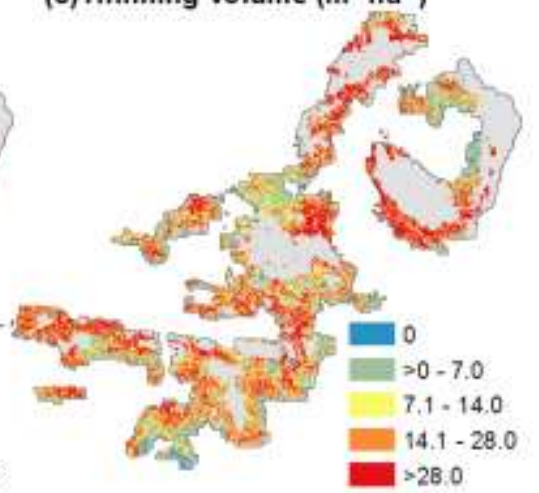

(f) Revenue ( $\$ \mathrm{ha}^{-1}$ )

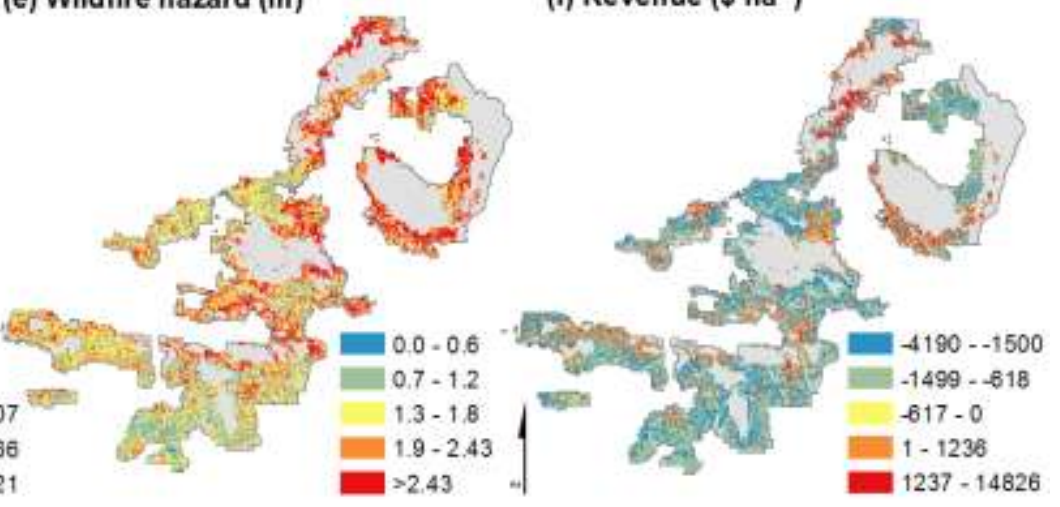

210 Fig. 4. Spatial distribution of restoration objectives in the study area. (a) forest departure, (b)

211 insect risk, (c) merchantable timber volume generated from restoration thinning, (d) structure

212 exposure in the wildland urban interface from national forest (NF) ignited wildfires, (e) wildfire 
213 hazard, and (f) revenue from restoration treatments. See Section 2 for details on the estimation of 214 each variable.

215 2.6. Wildfire Exposure to the Urban Interface

216 We measured wildfire transmission risk to WUI adjacent to national forests in the study area 217 using methods found in Ager et al. (2014) and as described in Appendix A. We used SILVIS

218 WUI data (Radeloff et al., 2005) for the study area, but removed SILVIS polygons that were 1)

219 classified as uninhabited, 2) classified as water, 3) $<0.1$ ha in size, or 4) $>10 \mathrm{~km}$ from the

220 national forest boundary. This included polygons with very low structure densities to correspond

221 with current fire suppression efforts that aim to protect even individual structures in wildland

222 areas. There were 52,202 WUI polygons containing structure density data covering an area of

223 over 1.6 million ha.

224 We used wildfire simulation outputs generated from FSim (Finney et al., 2011) to quantify

225 area of WUI burned by ignitions located on adjacent national forests. Detailed simulation

226 methods can be found in Finney et al. (2011) and Appendix B. FSim produces both polygon-

227 based fire perimeters and ignition points for each simulated fire. Ignitions were filtered for those

228 occurring within national forest boundaries and associated perimeters were intersected with WUI

229 boundaries to determine WUI area burned annually by each ignition. Total WUI area burned per

230 stand was calculated by summing contributions from all ignitions reaching that stand. We

231 estimated annual structures affected by each national forest-ignited fire as the product of the

232 housing units within each stand and the proportion of the polygon burned. The resulting point

233 data were smoothed using an inverse distance weighting model to generate a continuous $0.5 \mathrm{~km}$

234 raster grid using a $5 \mathrm{~km}$ fixed search radius for the entire study area. The resulting raster was

235 resampled to $10 \mathrm{~m}$ and mean structure exposure (Fig. 4D) was attributed to each stand. 


\subsection{Thinning Volume}

237 Thinning volume was estimated for each forested stand by processing tree lists with the

238 Forest Vegetation Simulator (FVS, Dixon, 2002). Tree lists for the study area were obtained

239 from the LEMMA project that used an imputation process to extrapolate forest inventory data

240 (FIA, Roesch and Reams, 1999) data to $30 \mathrm{~m}$ x $30 \mathrm{~m}$ pixels using a gradient nearest neighbor

241 (GNN) procedure (Ohmann and Gregory, 2002)(Appendix A). We simulated a restoration

242 thinning in each stand using the Blue Mountains variant of FVS (Keyser and Dixon, 2015).

243 Thinning prescriptions were adopted from operational practices by local national forest

244 silviculturists, which were developed in detail in previous studies (Ager et al., 2007; Barbour et

245 al., 2005). Thinning prescriptions prioritized removal of smaller trees to reduce ladder fuels, in

246 order to prevent torching and crowing fire behavior. Additionally, prescriptions targeted removal

247 of late-seral, fire-intolerant species (e.g., grand fir) and retention of fire tolerant early seral

248 species (e.g., ponderosa pine). Stand conditions that resulted in a thinning treatment were based

249 on thresholds for stand density index (SDI, Cochran et al., 1994) and density of small trees.

250 Maximum SDI values were assumed for each plant association group as described by Cochran et

251 al. (1994). If SDI exceeded $45 \%$ of the maximum SDI for plots in the plant association group, we

252 simulated a thinning from below to achieve a post-thin stocking of $35 \%$ of the maximum SDI.

253 Maximum tree harvest size was $53.3 \mathrm{~cm}$ as specified in local harvest guidelines (USDA and

254 USDI, 1994). A second filter was applied to treat stands that did not meet the SDI threshold but

255 had high density of small trees. Specifically, if stand density was less than $45 \%$ of the maximum

256 SDI but there were greater than 741 trees per hectare (TPH), with diameters ranging from 0.25

$257 \mathrm{~cm}$ to $17.78 \mathrm{~cm}$ at breast height (DBH), the stand was thinned to $333 \mathrm{TPH}$ (approximately $5.5 \mathrm{~m}$ 
258 between trees) with a $53.3 \mathrm{~cm}$ maximum harvest size. FVS outputs were assigned to each GNN

259 pixel and the total thinning volume per stand was calculated by summing the individual values.

260

261

262

263

264

265

266

267

268

269

270

271

272

273 calculated based on slope and tree size class consistent with methods used in previous studies

274 (Rainville et al., 2008; Rummer, 2008). Ground-based harvesting system (Table 2) was assigned

275 for stands having a slope less than or equal to 35\%, and a cable harvesting system (Table 3) was

276 assigned for all stands that exceed the $35 \%$ threshold. Average slope per stand was calculated

277 from digital elevation data $(30 \times 30 \mathrm{~m})$. Hauling distances were calculated using Euclidian

278 distance to the nearest wood processing facility. Although this approach generated downward-

279 biased estimates of distance, the approach was deemed adequate for the current study. We

280 assumed an average transportation speed of $70 \mathrm{kph}$, an operational trucking cost of $\$ 85.00$ per 
281 hour, and an average $\log$ load of $17 \mathrm{~m}^{3}$ per truck (Mason et al., 2008). Hauling costs were

282 calculated as:

283

$$
\frac{\text { Distance to nearest mill }(k)}{70 \mathrm{kph}} \times \frac{\$ 85.00}{\mathrm{hr}} \times \frac{\text { Total merc h.volume }\left(\mathrm{m}^{3}\right)}{17 \mathrm{~m}^{3} \text { per truck }} \times 2
$$

284 Note that hauling cost was only calculated for stands that generated greater than $28 \mathrm{~m}^{3} \mathrm{ha}^{-1}$ of

285 merchantable timber, and considered the round trip distance to the nearest mill.

286 Stands that were treated to meet fire protection goals were assessed additional fixed costs to

287 account for those treatments. For stands that generated greater than $28 \mathrm{~m}^{3} \mathrm{ha}^{-1}$, we assumed $40 \%$

288 of the stand would require additional fuel treatment at a cost of $\$ 1,112 \mathrm{ha}^{-1}$. If a stand was

289 triggered for treatment and did not generate $28 \mathrm{~m}^{3} \mathrm{ha}^{-1}$, we assumed a fixed cost of $\$ 1,112.00 \mathrm{ha}^{-}$

$290{ }^{1}$ to treat residual fuel load. These cost parameters were derived from local transaction data on

291 the national forests. This approach ignored: 1) planning and contracting costs, 2) cost of road

292 maintenance and construction, 3) removal of non-merchantable volume generated from thinned

293 stands and marginally merchantable pulpwood material, and 4) underburning. These additional

294 costs were omitted because most are budgeted outside of the restoration planning process (i.e.,

295 Forest Service employee salaries), and activities such as road construction and re-construction

296 are not possible prior to project implementation.

297 To calculate residual value from treatments, the sum of harvesting, hauling, and fixed costs

298 was subtracted from total log pond value. Average and net revenue per stand were calculated

299 and used as a restoration objective in the trade-off analysis along with other restoration goals

300 previously described (Fig. 4F). Validation included a comparison of outputs with other published

301 and unpublished sources as tabulated in Appendix C.

\section{2.9. Spatial Optimization Model}


We used the Landscape Treatment Designer (LTD, Ager et al., 2012; Ager et al., 2013) to

304 model hypothetical restoration scenarios and identify trade-offs among different restoration

305 objectives (Appendix B). LTD has specific design features for prioritizing and optimizing spatial

306 fuel treatment patterns as part of restoration planning. LTD uses a stand polygon shapefile

307 attributed with restoration objectives. The user enters a restoration scenario by specifying

308 objectives (e.g., revenue), activity constraints (e.g., budget), and stand treatment thresholds (e.g.,

309 fire behavior), and the program identifies stands to treat such that:

$$
\operatorname{Max} \sum_{j=1}^{k}\left(Z_{j} * \sum\left(W_{i} N_{i j}\right)\right)
$$

311 Subject to:

$$
\sum_{j=1}^{k}\left(Z_{j} A_{j}\right) \leq C
$$

313 where $\mathrm{C}$ is a global constraint on activity per project area, $Z$ is a vector of binary variables

314 indicating whether the $j$ th stand is treated (e.g., $Z_{j}=1$ for treated stands and 0 for untreated

315 stands), $N_{i j}$ is the contribution to objective $i$ in stand $j$ if treated, and $A$ is the area of the $j$ th

316 treated stand. $W_{i}$ is a weighting coefficient that can be used to emphasize one objective versus

317 another. The LTD program can be used to solve optimization problems with or without

318 adjacency constraints. In the current application we used existing planning areas obtained from

319 national forests and used the program to identify stands to treat that maximized the objective,

320 while meeting constraints. Given multiple planning areas, the program iterates through each one,

321 then reports the maximum objective value and the selected treatment stands.

322 We prioritized each of the 102 planning areas in the study area based on restoration objective

323 (Appendix A), and simulated treatment of 5000 ha in each planning area to address one or more

324 of the restoration objectives described in section 2. Overstocked stands were assumed to generate

325 wood volume from thinning treatments, and surface fuels reduction (mastication and 
326 underburning) were also assumed to be part of the treatments where conditions met treatment

327 thresholds as described in section 2.9. It was assumed that each restoration objective (e.g., insect

328 risk, forest departure, wildfire hazard) would be addressed by these thinning and other

329 treatments, consistent with operational analyses of proposed restoration projects on US national 330 forests.

331 Trade-offs were analyzed between selected combinations of different objectives by changing 332 the relative weights of each objective (Eq. 2). These comparisons focused on trade-offs in

333 revenue from different restoration objectives. Here, integer weights were varied in all

334 combinations from 0 to 50 in increments of 10 in a pairwise fashion. Outputs were used to 335 generate production possibility frontier relationships between harvest volume and each objective.

336 For instance, weights of 10 and 0 for objective A and B, respectively, represent the maximum

337 production for objective A, whereas weights of 20 and 20 for each objective represent a mixed 338 production for both.

339 We used average per-area condition of each stand in the selection algorithm in order to 340 remove potential bias resulting from stand size. However, overall optimality of projects was

341 based on the total objective value calculated as the area weighted quantity (e.g., total thinning

342 volume) to account for differential contribution to the objective from stands of different sizes.

343 Thus, stands were added to project areas based on mean objective values for that stand, and once

344 the treatment constraint was met (5000 ha) the total objective value was summed for each stand

345 in the project. To standardize reporting of different metrics we calculated the percentage

346 contribution of attainment of each stand to the study area and summed these values for each

347 project, thus providing a standardized metric that could be compared among different objectives. 
We performed additional sensitivity analyses by analyzing cumulative attainment of

349 restoration objectives with increasing number of project areas under different restoration

350 objectives. We calculated net revenue under each optimization scenario as a function of the

351 increasing scale of restoration. Finally, to explore how maximizing revenue could increase the

352 scale of restoration activities we performed a sensitivity analysis whereby planning areas were

353 treated until revenues from profitable stands were expended to treat unprofitable areas up to the

354 breakeven point. In this analysis we incrementally added stands to each planning area in order of

355 decreasing profitability until net revenue was zero, and examined the extent to which restoration

356 treatments could be expanded by reinvesting revenue from profitable to unprofitable stands.

\section{3. Results}

Net revenue from restoration treatments (5000 ha in each planning area) ranged from a

359 high of $\$ 20.53$ million to a low of \$-7.38 million with most profitable areas on the Umatilla and

360 Wallowa-Whitman NFs. High revenue areas had a slight concentration in the northern portions

361 of the Umatilla and central Wallowa-Whitman NFs (Figs. 2, 5F), and thus potential value of

362 economic prioritization ranged from a high of \$26.7 million for the Umatilla NF and a low of

$363 \$ 8.9$ million for the Ochoco NF. In general, variation among planning areas on the Ochoco NF

364 was minimal compared to the Umatilla and Wallowa-Whitman. A similar pattern of variation

365 among planning areas within national forests was observed for insect risk and thinning volume,

366 but not for forest departure (Fig. 5). For all objectives, there are a number of instances where low

367 and high priority planning areas were adjacent, illustrating the magnitude of local variation of 
restoration opportunity in the study area.

(a) Forest departure

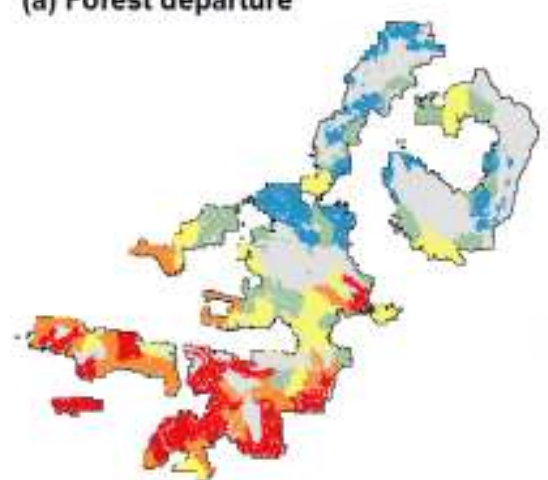

(d) Structure exposure from NF

369

370

371

372

373

374

375

relationships between revenue and other restoration objectives. In some planning areas,

378 attainment of one restoration objective was largely unaffected by the other (Fig. 6A, planning

379 areas 4, 12 and 13). In others, the trade-offs were symmetrical and concave to the origin (convex (b) Insect risk

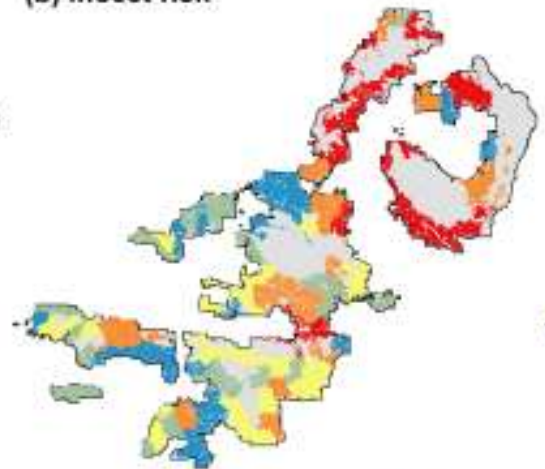

(e) Wildfire hazard

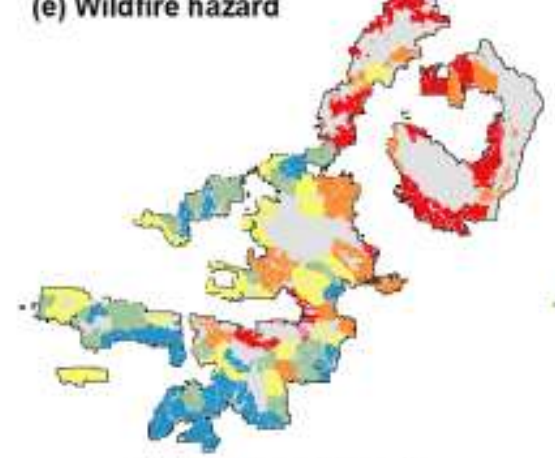

Planning Area Priority

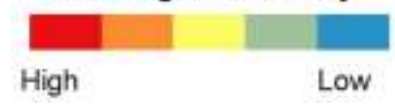

(c)Thinning volume

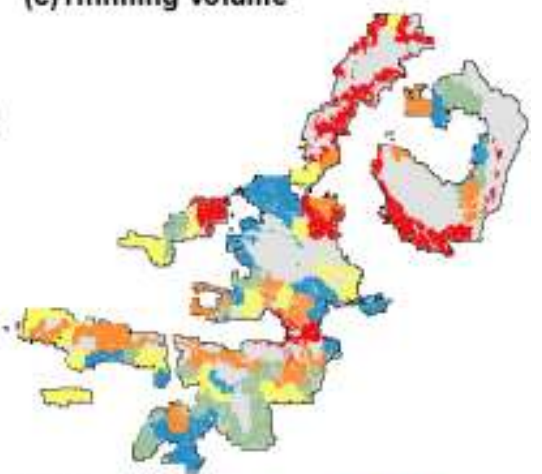

(f) Revenue

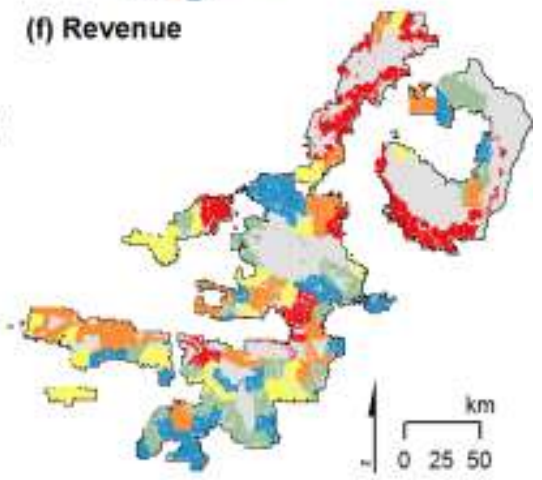

Fig. 5. Results from optimization modeling showing prioritization of the 102 planning areas in the study area for each of the six restoration objectives. (a) forest departure, (b) insect risk, (c) merchantable timber volume generated from restoration thinning, (d) structure exposure in the wildland urban interface from national forest (NF) ignited wildfires, (e) wildfire hazard, and (f) revenue from restoration treatments. Stands selected for treatment within each planning area maximize attainment of the restoration targets assuming treatments on 5000 ha.

Production possibility frontiers (PPF) (Figs. 6, 7) exhibited three broad trade-off 
to the outer surface; Fig. 6B, planning areas 251, 250, 247) or asymmetrical with sharp trade-offs

381 in one direction and not the other. In many planning areas, PPFs indicated sharp decision trade-

382 offs, where the marginal benefit from improving the attainment of one restoration objective

383 exceeded twice the loss in the other objective. By contrast, trade-offs between revenue and insect

384 risk (Fig. 6B) showed relatively small trade-offs within planning areas, and complementary

385 production among planning areas. Trade-off relationships were generally similar for revenue and

386 thinning volume (Figs. 6, 7), although economic factors such as transportation costs and

387 processing of sub-merchantable material resulted in some differences in the PPFs for particular

388 planning areas.
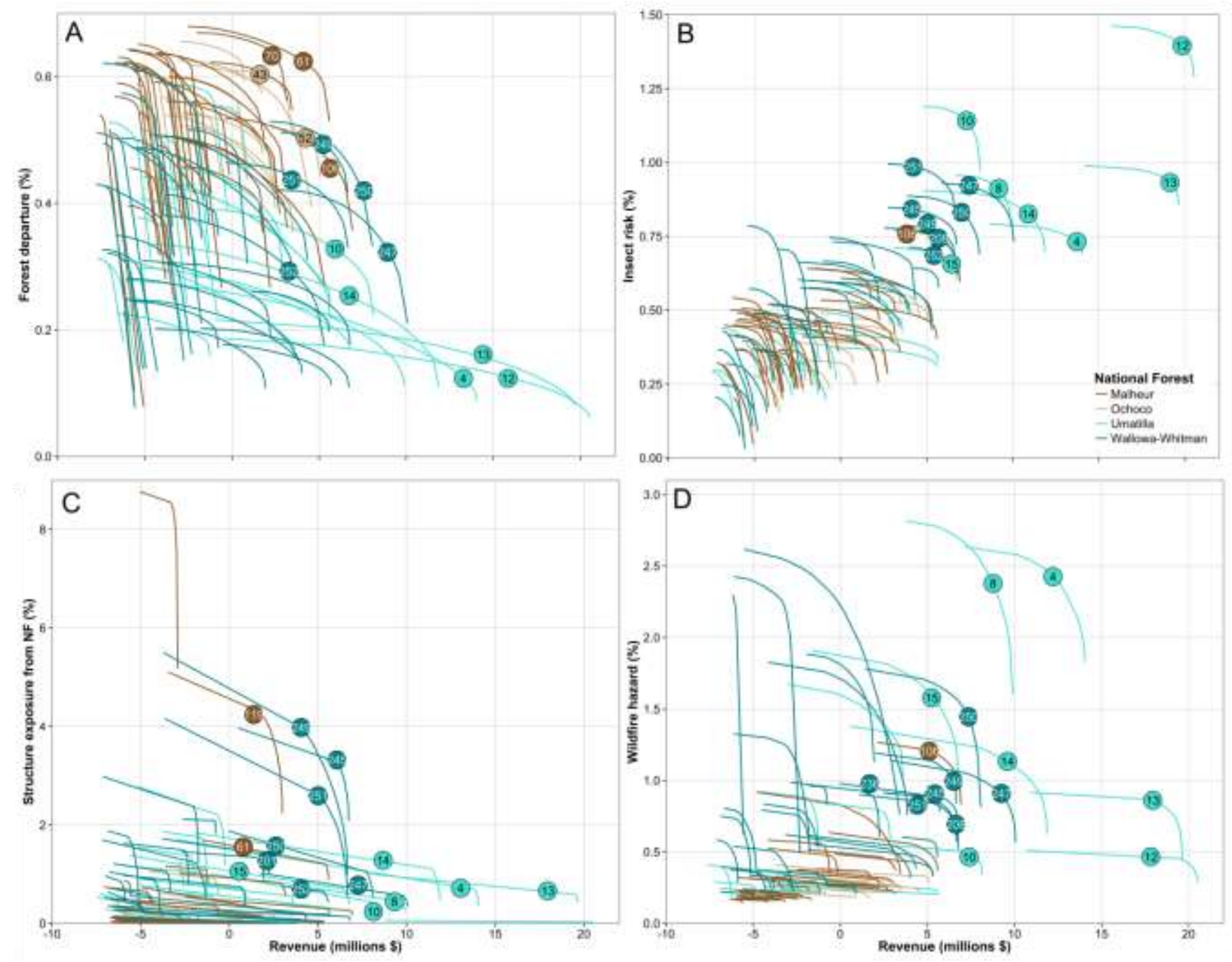
390 Fig. 6. Production possibility frontiers (PPF) for each of the 102 planning areas for revenue from 391 treatment versus each of the other restoration objectives: A) forest departure, B) insect risk, C) 392 structure exposure in the wildland urban interface from national forest (NF) ignited wildfires, 393 and D) wildfire hazard. PPFs are generated by optimizing the selection of stands to address one 394 or the other or both of the restoration objectives in each panel. Convex and symmetrical curves 395 indicate opportunity for restoration to accomplish multiple objectives. Asymmetrical curves 396 show that optimal joint production favors one objective over the other.

397 A number of forest-scale differences were apparent in PPF relationships. Specifically, there 398 was substantially more opportunity on the Umatilla and Wallowa-Whitman to produce revenue 399 and treat wildfire transmission to WUIs (Fig. 6C) compared to the Ochoco and Malheur.

400 Likewise, generating revenue and treating forest departure was feasible on the Wallowa401 Whitman but not the Malheur (Fig. 6A).

402 Trade-offs among planning areas within the ecoregion as a whole can be visualized by 403 tracing the outer (right) bounds of individual PPFs (Figs. 6, 7), thus providing insights into scale 404 effects on restoration opportunity. It can be seen that an aggregate PPF among all planning areas 405 was either linear (Figs. 6B, 7B), convex to the origin (Figs. 6C, 7C), or concave to the origin 406 (Figs. 6D, 7D), compared to concave for individual planning areas. Trade-offs at the ecoregion 407 scale for forest departure and wildfire hazard had a more or less concave form, while structure 408 exposure from national forest lands was convex, the latter suggesting sharper trade-offs among 409 restoration opportunities at larger scales. By contrast, insect risk has a linear form as a result of 410 correlation between risk and timber volume inherent in the calculations. Thus, increasing the 411 scale of prioritization assessments presents different trade-offs to stakeholders and managers. 
Optimal rates of attainment for each objective were examined by first determining the

413 optimum schedule of planning areas and then calculating the cumulative attainment as treatments

414 were implemented in each planning area, from highest to lowest priority (Fig. 8A). The rate of

415 attainment under different optimization scenarios was non-linear, especially for revenue and

416 wildfire hazard (Fig. 8A). About $60 \%$ of the total structure exposure could be treated on 100,000

417 ha (20 planning areas)(Fig. 8A). By contrast, treating the same area under a scenario where

418 treating forest departure was the primary objective addressed only $10 \%$ of the total departure in

419 the study area. The differential rates of attainment resulted from spatial patterns of restoration

420 targets within and between planning areas.
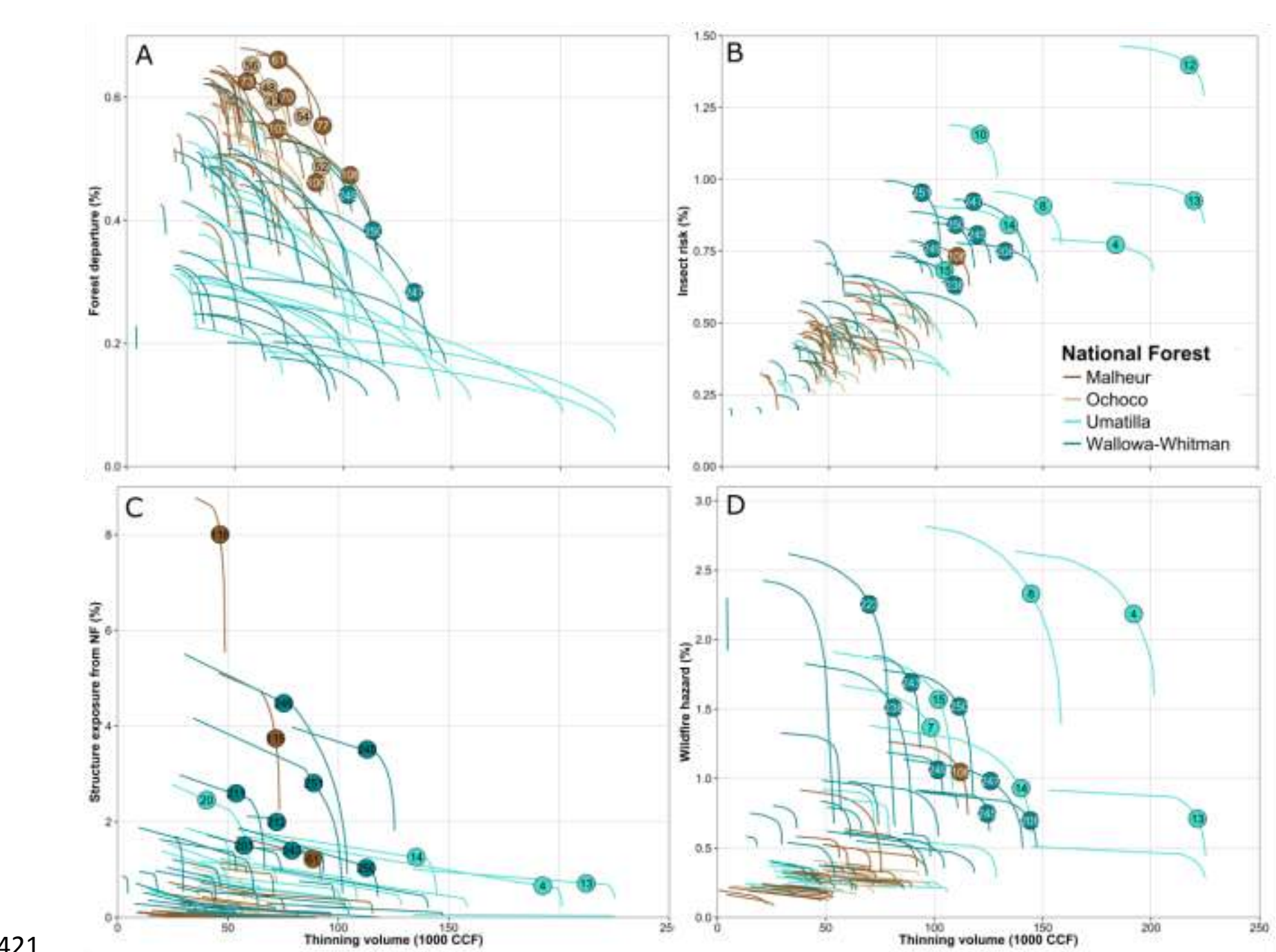

421 
422 Fig. 7. Production possibility frontiers (PPF) for each of the 102 planning areas for thinning

423 volume generated from treatment versus each of the other restoration objectives: A) forest

424 departure, B) insect risk, C) structure exposure in the wildland urban interface from national

425 forest (NF) ignited wildfires, and D) wildfire hazard. PPFs are generated by optimizing the

426 selection of stands to address one or the other or both of the restoration objectives in each panel.

427 Convex and symmetrical curves indicate opportunity for restoration to accomplish multiple

428 objectives. Asymmetrical curves show that optimal joint production favors one objective over

429 the other.

430 We plotted cumulative attainment for each of the restoration objectives under a revenue optimization

431 scenario to understand the economics of ecological objectives (Fig. 8B). Here, planning areas were

432 implemented based on net revenue (high to low) and the cumulative attainment of the other objectives

433 was measured (Fig. 8B). As expected, attainment was substantially less (40-60\% reduction depending on

434 the objective) compared to scenarios where they were individually optimized (Fig. 8A), the exception

435 being thinning volume where reduction in attainment was relatively minor (5-10\% reduction). Cumulative

436 revenue initially increased with increasing treated area until 250,000 ha of treatment, and then declined as 
437 planning areas with negative revenues were added to the scenario.
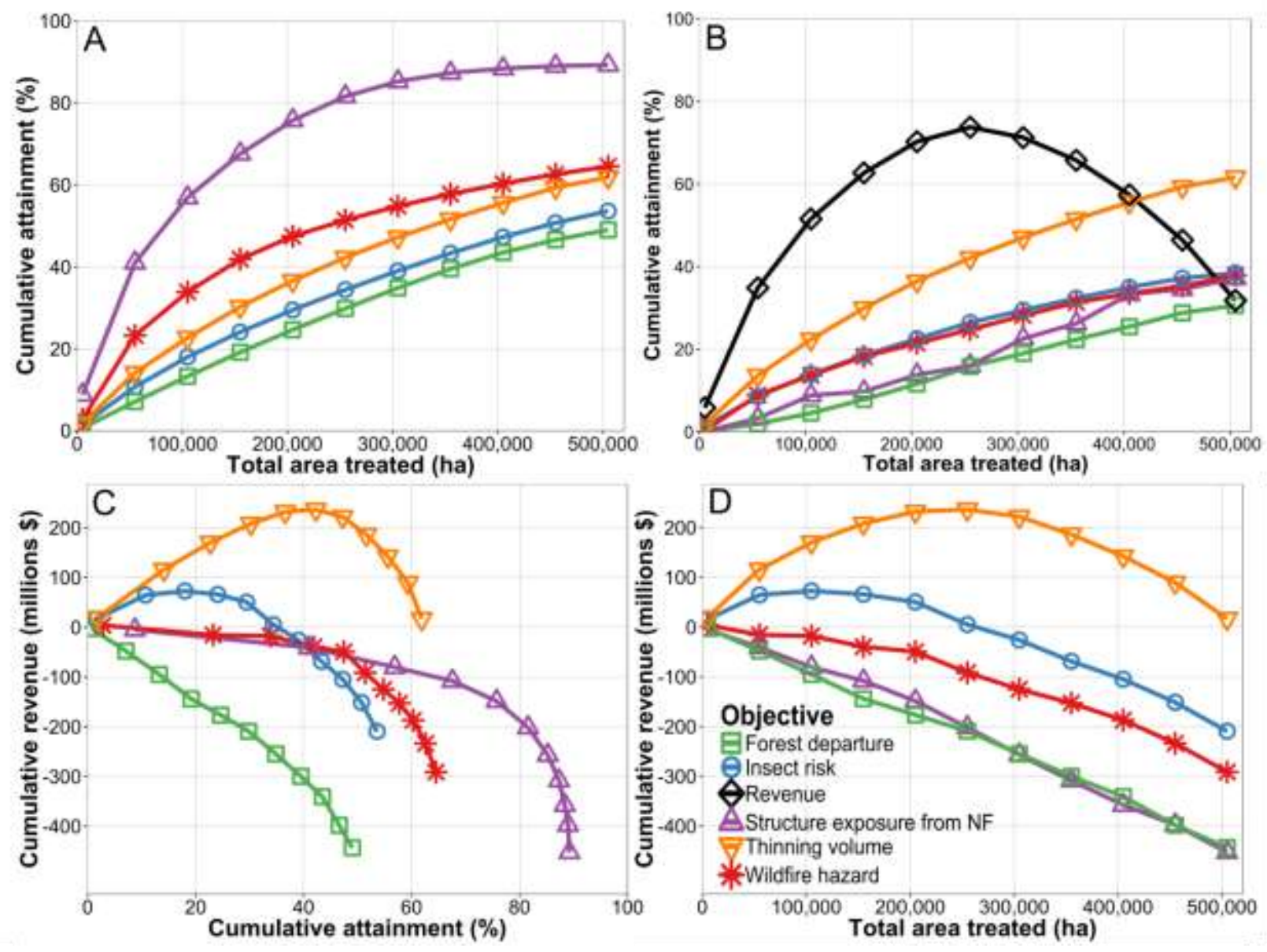

439 Fig. 8. Comparison of net revenue and restoration attainment among planning areas under

440 alternative prioritization scenarios. A) Cumulative attainment of the five objectives when each of

441 them are individually prioritized; B) same as A when revenue is prioritized; C) the revenue

442 associated with levels of attainment when each of the objectives are prioritized; and D)

443 cumulative revenue as a function of total area treated. Attainment is measured as the total

444 inventoried quantity of each of the restoration goals on the landscape.

445 To examine costs for achieving specific levels of each restoration objective we plotted

446 revenue versus attainment for each optimization scenario (Fig. 8C). Comparing Figs. 8A and 8C

447 it is possible to identify the economic cost or benefit of different restoration priorities. 
448 Prioritizing forest departure was the costliest restoration objective where treating $50 \%$ of the 449 departure in the study area would cost about $\$ 450$ million (Fig. 8C). By contrast, $60 \%$ of the 450 available wood volume from thinning operations could be obtained at a net cost of $\$ 0$. About $45150 \%$ of the total structure exposure can be treated at a cost of $\$ 58$ million. Prioritizing restoration 452 treatments on areas of high insect risk resulted in positive revenue until cumulative attainment 453 reached 35\% (Fig. 8C) at which point treatments would be implemented on 265,000 ha. 454 In Fig. 8D we show the relationship between treated area and revenue when the latter is 455 optimized as in Fig. 8B. These data can be used to understand the economics of scale in 456 prioritizing restoration objectives, i.e., the cost or revenue to treat specific levels of restoration 457 targets as suggested in restoration assessments (Haugo et al., 2015). For instance, treating 458500,000 ha under a revenue optimization scenario would break even financially (Fig. 8D, 459 thinning volume) and treat $25 \%$ of the forest departure in the study area (Fig. 8B). By contrast, 460 treating the same area under a scenario where forest departure (versus revenue) was prioritized 461 (Fig. 8A) the attainment was increased by 15\%. About $40 \%$ of the total forest departure would 
462 require implementing projects on 365,000 ha (Fig. 8C) at a total cost of $\$ 300$ million.
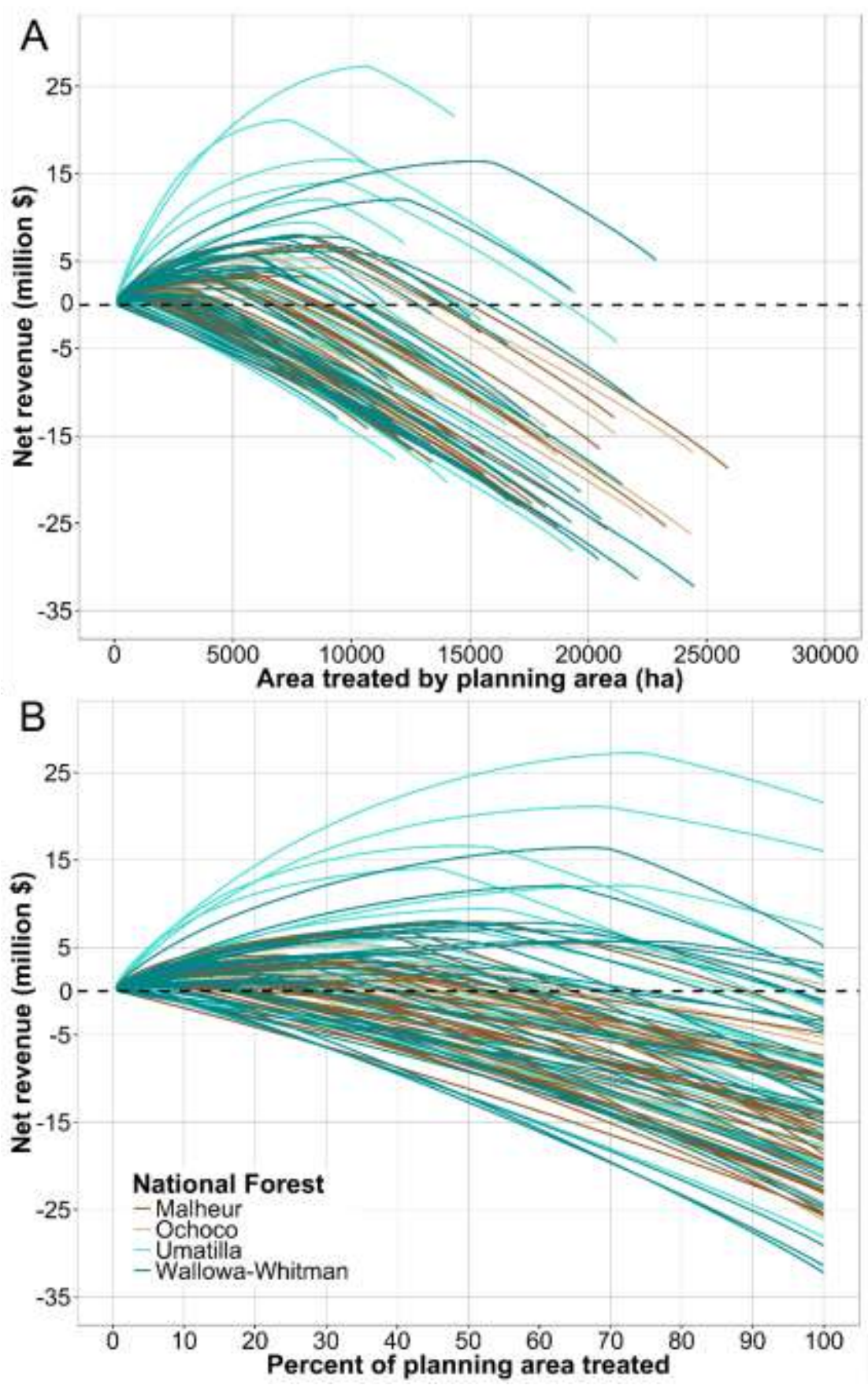

463

Fig. 9. Effect of treatment area on net revenue for each of the 102 planning areas in the study

465 area under a revenue maximization scenario. (A) Revenue generated with increasing area treated

466 by planning area; and (B) revenue versus percent of the planning area treated. The point of 0 
467 revenue $(\mathrm{Y}=0)$ shows the maximum area that can be treated per planning area at no cost, thus 468 maximizing area restored per project.

469 We analyzed the relationship between restoration effort (treated area per planning area) and 470 economic viability to examine variability in optimal treatment intensities. We performed this 471 economic sensitivity analysis by incrementally adding stands to the treated pool in each planning 472 area in order of decreasing profitability. The results revealed economic optima at a range of 473 treatment intensities, and that many of the planning areas do not contain stands that have the 474 potential to generate positive revenue (Fig. 9). Mean treated area at the revenue optima was 475 about $26.7 \%$ (Fig. 10), compared to $43.3 \%$ at the break-even point (net revenue $=0$ ). This latter 476 treatment intensity represents a scenario where revenue from profitable stands is re-invested to 477 maximize the area treated and post-treatment fire resiliency per planning area. The increase in 478 final area treated under the two different scenarios, maximizing revenue versus maximizing area 479 treated without investments (Fig. 10), varied among the planning areas and averaged 2478 ha $480(17 \%)$. 


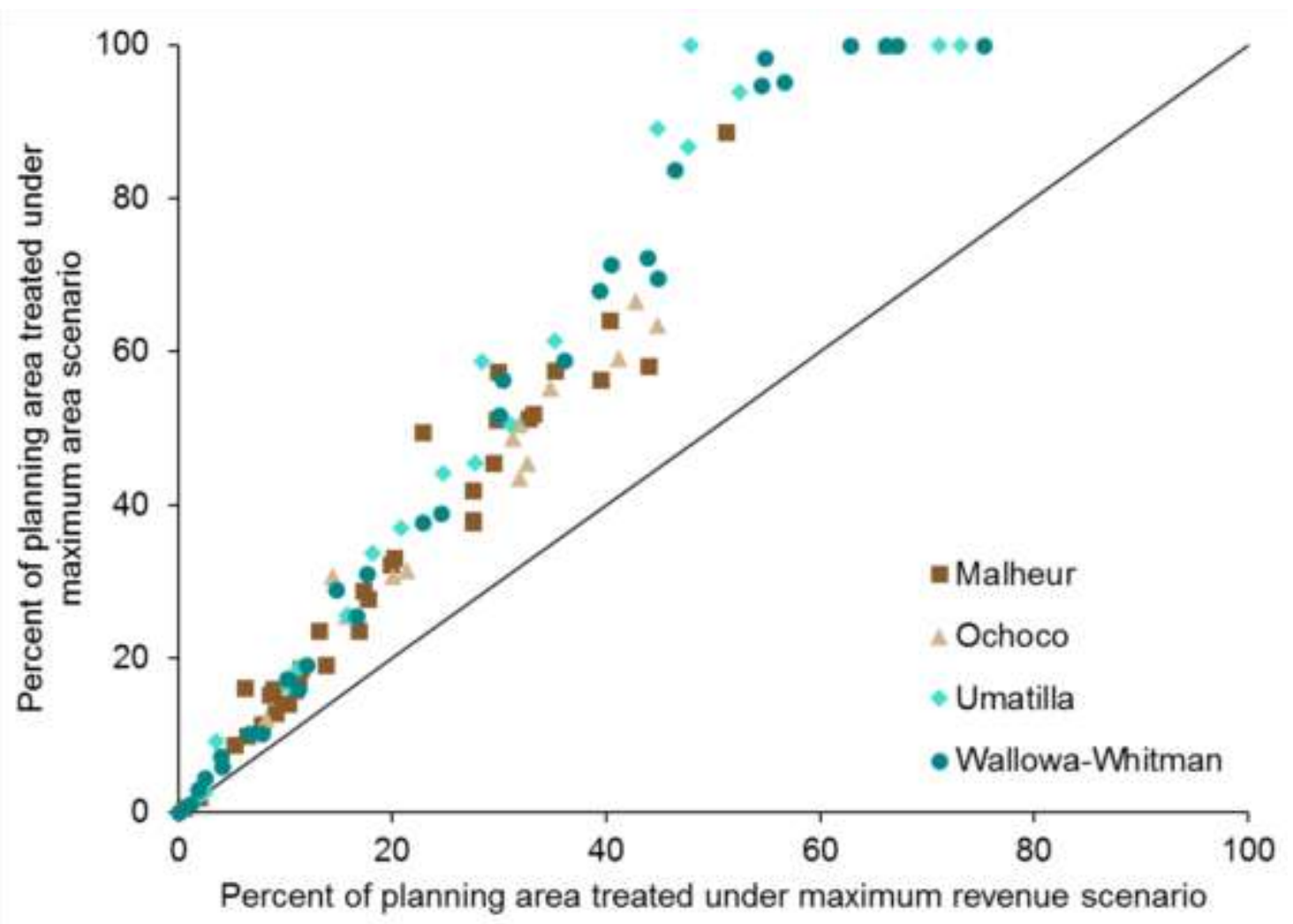

482 Fig. 10. Percentage area treated by planning area under two scenarios showing the increased

483 treatment area when revenue is re-invested within planning areas to maximize area treated, i.e.

484 revenue from profitable stands is used to subsidize treatment of stands that do not generate 485 revenue but require restoration treatment (mechanical thinning, fuels mastication). The increase 486 in treated area averages 2478 ha per planning unit (17\% increase). The average area treated per 487 planning area is estimated at $26.7 \%$ when revenue is maximized, and $43.3 \%$ if revenue is re488 invested to treat stands that do not generate sufficient revenue for harvesting and treatment costs.

\section{4. Discussion}

490 Two major challenges in forest restoration planning are balancing the broad mix of 491 socioeconomic and ecological goals, and funding restoration management where economic 492 returns are not possible. In the case of restoration on national forests in the US, both challenges 
493 are amplified by diverse stakeholder interests that are vetted through a legislated collaborative

494 planning process. The importance of economic prioritization and the identification of cost

495 efficient areas for restoration of ecosystem services has been widely discussed for a number of

496 ecological restoration problems (Adame et al., 2015; Kimball et al., 2015; Wilson et al., 2012),

497 including implications of inefficient prioritization (Iftekhar et al., 2016). However, only recently

498 have restoration scientists and practitioners begun to include economic aspects in the design of

499 restoration projects (Blignaut et al., 2014).

500 In our study, we found the economic viability of restoration projects is tenuous under current

501 practices, as noted in earlier studies (Barbour et al., 2008a; Haynes et al., 2001), and that

502 optimizing revenue to help finance restoration projects leads to a sharp reduction in the

503 attainment of other socioecological objectives, especially reducing ecological departure from

504 historic conditions (Haugo et al., 2015). However, production possibility frontiers were highly

505 variable among planning areas and national forests, and point to specific spatial priorities and

506 opportunities to achieve restoration goals within the study area. Under assumptions of static

507 landscape conditions, restoration attainment shows non-linear, diminishing returns in terms of

508 restoration objectives and revenue as projects are implemented over increasingly larger areas.

509 The current study builds on our previous research (Vogler et al., 2015) by adding an

510 economic analysis that shows the cost of specific restoration objectives and levels of attainment

511 in terms of percentage of the restoration objective or area treated. We expanded the scale and

512 scope compared to earlier work (Vogler et al., 2015) to quantify variability in production

513 possibilities and decision trade-offs at the ecoregion. Optimization modeling was simplified

514 compared to Ager et al. (2016) concerning the same study area, by predefining planning areas

515 rather than using spatial optimization algorithms to build them. This latter modification 
516 simplifies field application of our methods by restoration planners to prioritize projects on

517 national forests.

518 This work contributes to achieving long-term social and ecological goals for US national

519 forest restoration programs, and communicating benefits of restoration efforts (Mentz et al.

520 2013). The importance of analyzing economic tradeoffs from Forest Service restoration

521 programs is underscored by the fact that agency budgets specify annual wood volume targets

522 (3.2 billion board feet in FY 2016), and the ecological tradeoffs from attaining this production

523 level are not known. Our economic analyses corroborate earlier studies that show challenging

524 economic opportunities for restoration programs (Barbour et al., 2008a; Beck Group, 2015;

525 Rainville et al., 2008). Specifically, we showed diminishing returns for generating thinning

526 volume as restoration activities were implemented at increasingly larger scales.

527 Identifying economic opportunities from national restoration programs would seem to be a

528 key step in collaborative planning, since revenue from harvested wood can support non-

529 economic restoration (e.g., riparian restoration, invasive plant control) to sustain ecosystem

530 services from US national forests (Deal et al., 2012; USDA Forest Service, 2012). The

531 juxtaposition of ecological settings with human values generates sharp trade-offs, especially with

532 respect to community wildfire protection versus generating revenue to support restoration and

533 fire hazard reduction outside of areas that affect WUIs. Thus, opportunity costs for increasing

534 efforts for community wildfire protection impact progress towards reducing ecological departure

535 and long-term reintroduction of fire, and generation of thinning volume. This complicates

536 prioritization of restoration programs for economic objectives, which aim to generate revenue to

537 both support expanded restoration activities in areas that will not generate positive revenues, and

538 improve community resilience in rural areas (USDA-USDI, 2014). 
539 Our findings contribute in several ways to ongoing restoration programs in fire prone

540 national forest landscapes. First, we present the first economic analyses of restoration where

541 thinning activities were modeled at the stand-scale using actual planning area boundaries. These

542 facsimile projects capture local spatial variation that is not represented in coarse-gridded forest

543 inventories used in past economic studies (Hartsough et al., 2008). Thus our financial analysis of

544 forest restoration incorporated contagion, or lack thereof, of restoration opportunity not

545 considered in earlier studies. Scale-related issues caused spatial packaging of thinning volume

546 and other restoration objectives that can be minimized by using finer-scale modeling approaches

547 than those typically used for restoration assessments. This modeling approach can provide more

548 realistic assessments of the production of provisional ecosystem services that can potentially

549 perpetuate restoration programs and meet socioeconomic goals. Second, we show that decision

550 trade-offs are scale-dependent and exist within planning areas, among planning areas, and among

551 national forests, making prioritization of restoration activities a multi-scale problem. Scale-

552 dependent trade-offs are not articulated in regional or national assessments (Barbour et al.,

553 2005), nor to our knowledge quantitated and exposed in collaborative planning efforts. We

554 believe that scale-dependent variations in PPFs are important to recognize in agency initiatives to

555 accelerate restoration initiatives. For instance, locally optimal PPFs, as determined by

556 collaborative groups or by optimal joint production on a PPF, may not lead to optimal outcomes

557 at larger (e.g., agency wide) scales. The former maximize the utility of stakeholder preferences,

558 but may lead to inefficient outcomes at larger scales.

559 The effect of scale on PPFs was evident among all the variables tested. For instance, we

560 noted production frontiers within a planning area were concave (Fig. 6, 7), versus linear or

561 convex among planning areas (Fig. 8) and national forests (Fig. 9). Thus, local optimization of 
562 restoration objectives presents a shallower trade-off compared to trade-offs among planning

563 areas, among national forests, and at the bioregional scale of planning. Change in production

564 functions with geographic scale in terms of shape (convex versus concave) and magnitude has

565 heretofore not been explored. While our finding that larger scales present more choices for

566 restoration programs is not surprising, we note that the change in trade-offs was not consistent

567 among all restoration objectives studied. The hierarchy of trade-offs creates unique restoration

568 storylines for individual national forests and planning areas within them.

569 A number of management guidelines, frameworks, and strategic visions have been

570 written about restoration and contemporary forest management (Franklin and Johnson, 2012;

571 Franklin et al., 2013; Stine et al., 2014; USDA Forest Service, 2015b). However, detailed

572 forecasts on the rate of treatment to achieve specific restoration goals and information on

573 resources required to attain them are largely nonexistent, especially for activities such as

574 thinning, burning, and economic value and raw wood materials. In fire-prone forests of the

575 Pacific Northwest, forest restoration efforts were initially guided by watershed scale ratings of

576 restoration need (Rollins, 2009), and later replaced with more comprehensive work by Haugo et

577 al. (2015) on ecological departure at subwatershed scales. By contrast, our work clearly shows

578 variation among and within planning areas and national forests in terms of potential restoration

579 attainment and trade-offs among multiple objectives for restoration programs. These trade-offs

580 were particularly sharp between ecological restoration and socioeconomic objectives, including

581 fire transmission among public and private land parcels. The relatively large geographic scale of

582 the study allowed us to begin to understand restoration storylines for each national forest, and

583 demonstrate a prioritization process that can be used at multiple scales (stands, planning areas,

584 national forests, ecoregions). National forests throughout the western US are surrounded by 
585 unique timber-dependent communities and socioecological settings (Paveglio et al., 2009), and

586 restoration efforts must be balanced among national forests to meet expectations of forest

587 collaborative groups (Butler et al., 2015) and broad social expectations of restoration programs

588 (Franklin et al., 2014). Moreover, articulating spatial priorities and trade-offs in US national

589 forest restoration is of growing importance given that: 1) suppression expenditures are depleting

590 restoration funds (USDA Forest Service, 2014), and 2) there is a growing importance to

591 communicate priorities to stakeholders within rapidly expanding collaborative planning groups

592 (Butler et al., 2015) that help set local priorities for restoration.

593 Biophysical restoration trade-offs stem from the diversity of forest conditions that evolved

594 from past management, biophysical setting, and disturbances such as wildfire. The net result of

595 these anthropogenic and natural factors is a reduction in the spatial covariation for some

596 restoration targets but not others. Spatial correlation between ecological departure, provisional

597 ecosystem services, and community wildfire protection issues is perhaps more diffuse than

598 assumed by policymakers, especially those related to spatial patterns of socioeconomic values.

599 We observed and quantified trade-offs at the scale of national forests, planning areas, and among

600 stands within planning areas, all of which are useful outputs to examine alternative restoration

601 priorities. These trade-offs are the root cause of conflicts in local and regional planning, and thus

602 understanding their spatial organization is key to resolving conflicts in participatory planning

603 used in forest restoration (Butler et al., 2015). Understanding management trade-offs and how

604 joint spatial distributions of both stressors and ecosystem services contribute to these trade-offs

605 on large landscapes is arguably an important component of restoration planning (Allan et al.,

606 2013; Bennett et al., 2009; Schroter et al., 2014). Studies on trade-offs and spatial prioritization

607 in conservation biology and natural resource literature cover a diverse range of ecosystems and 
608 associated services (Cattarino et al., 2015; Chhatre and Agrawal, 2009; Hauer et al., 2010;

609 Maron and Cockfield, 2008; Schroter et al., 2014; White et al., 2012).

610 We note several limitations in our assumptions and modeling. In particular, our approach for

611 assessing revenues from restoration programs should be considered in its relative context rather

612 than absolute values. Treatment costs are affected by a wide range of factors. Our methodology

613 estimated costs associated with logging and hauling operations but ignored: 1) planning and

614 contracting costs, 2) cost of road maintenance and construction, 3) removal of non-merchantable

615 volume generated from thinned stands and marginally merchantable pulpwood material, and 4)

616 underburning. In addition, it is not possible to estimate acceptable profits, risk, and overhead

617 rates for industrial entities that perform fuel management operations (Rummer, 2008).

618 Estimating cost of fuel treatment programs is complicated by the fact that operations typically

619 involve many different types of equipment and treatment methods applied to a range of stand

620 conditions in terms of both physical setting and stand structure (Rummer, 2008). Our analysis

621 found similar results for cost and net revenue of forest restoration operations as previous studies

622 that used both engineering cost analysis (Rainville et al., 2008) and transaction evidence (Beck

623 Group, 2015) methodologies.

624 Specifically, we compared our results to several independent data sources and in general

625 found reasonable agreement. These comparisons focused on individual analyses of the four

626 economic subsystems (harvest costs, overstocked forested area, total volume production, and net

627 project revenue). In terms of harvest costs, our average of $\$ 27.90 \mathrm{~m}^{-3}$ for all harvested stands was

628 close to that obtained in a recent five-year cash flow survey of all timber sales in the study area

629 (\$26.50 $\mathrm{m}^{-3}$, Robert Schatz, Ochoco National Forest, personal comm.). The area of overstocked

630 stands was similar to that reported by Barbour et al. (2008a) for Morrow, Umatilla, and Grant 
631 counties for both number of overstocked hectares and potential merchantable volume from

632 thinning treatments. However, we found large discrepancies for both metrics in Baker, Harney,

633 Union, Wallowa, Crook, and Wheeler counties. Differences in estimation may be a result of

634 relatively few plot samples in Rainville et al. (2008) where for instance, county scale estimates

635 were derived from a single plot. Moreover, the modeling contained a technical error in thinning

636 prescription where the calculation of post-thin stand density index was not adjusted to account

637 for the fact that trees $>53.3 \mathrm{~cm}(21 \mathrm{inch}) \mathrm{DBH}$ are not available to thin, and thus smaller trees

638 must be thinned below SDI thresholds to achieve the target SDI. Excluding this correction would

639 lead to underestimating potential volumes in all stands that contain larger tree size classes.

640 Differences in the modeled appraised value from our analysis and the price that a timber

641 contractor will be willing to pay for a particular sale (timber receipts) are not only influenced by

642 market value of timber minus costs but also desired profit margin, risk preferences, overhead

643 rates and bidding competition. Forest Service reports on total volume and value (timber sale

644 receipts) show an average value of $\$ 347.20 \mathrm{ha}^{-1}$ and $\$ 63.77 \mathrm{~m}^{-3}$ for all timber sale receipts within

645 the study area from 2008 to 2015 . From a simulation run of the same level of treated area

$646(83,779 \mathrm{ha})$ we found an average value of $\$ 882.99 \mathrm{ha}^{-1}$ and $\$ 17.29 \mathrm{~m}^{-3}$. Our estimates of timber

647 value should therefore be viewed as the maximum potential value a contractor would be willing

648 to pay for a timber sale and not an estimate of future potential harvesting receipts.

649 In addition to economic limitations, our simulation of projects within planning areas required

650 a number of assumptions. The implementation of restoration projects on national forests is driven

651 by many factors including legislation, case law, budget appropriations, and conflicts over the

652 production of ecosystem services. Our hypothetical projects assumed that activities would fall

653 within constraints posed by these factors. Modeling forest restoration programs can only include 
654 a subset of these drivers, and furthermore, a number of assumptions were required to simulate

655 implementation of restoration projects. These included: 1) stands selected for active restoration

656 would receive an appropriate suite of treatments including mechanical thinning, fuels

657 mastication, and underburning, thereby addressing the particular issue at hand; and 2) treatments

658 substantially reduced ecological departure, insect and disease issues, wildfire exposure to WUI,

659 and generated raw wood material from thinning, much the same way that planners assume

660 accomplishment towards restoration targets in operational settings (Brown et al., 2004). We

661 recognize that modeled outputs and identification of stand-scale prioritization represents a

662 general guideline for planners and that information on local conditions and constraints for

663 biodiversity and amenity protection will be part of a downscaling process to adjust outputs to

664 local conditions.

665 Restoration planning on national forests is a multiscale process where policy must be

666 downscaled to forests, landscapes, stands, and tree neighborhoods (Larson and Churchill, 2012),

667 creating a cascading series of decision trade-offs at each step. Current planning under the

668 Collaborative Forest Landscape Planning Act (Butler et al., 2015) in general consists of

669 participants expressing priorities to federal forest managers, and eventually decisions about

670 priorities and projects lead to implementation. As such, collaborative restoration planning lacks

671 analytical frameworks to examine important trade-offs among restoration priorities. Cavender-

672 Bares et al. (2015) proposed an interesting analytical protocol as part of a sustainability

673 framework that leveraged production possibility frontiers in collaborative planning where utility

674 functions for different stakeholder groups are superimposed on PPFs to maximize utility for each

675 stakeholder group (Fig. 11). Utility functions integrate values and services that stakeholders

676 associate with different levels of services in the production possibility frontier. Stakeholder 
677 groups can be characterized by utility functions that represent their core resource values in

678 relation to national forests as they affect their quality of life, economic livelihood, and risk from

679 natural disturbance on adjacent national forest lands. Divergence among stakeholders in

680 restoration planning stem from dependencies on different mixes of social, economic, and

681 ecosystem services generated on national forests, such as recreation and wood products. The

682 challenge with applying this approach for restoration programs on national forests is that large

683 decentralized agencies will have utility functions that vary by scale, and thus national policy

684 objectives as represented in utility functions would likely vary for stakeholder groups involved in

685 local planning. Future refinements in restoration planning, including application of methods we

686 present here and socioeconomic modeling of the collaborative planning process, will in the long-

687 run facilitate implementation of restoration policies on US public lands and adjacent fire adapted 688 landscapes.

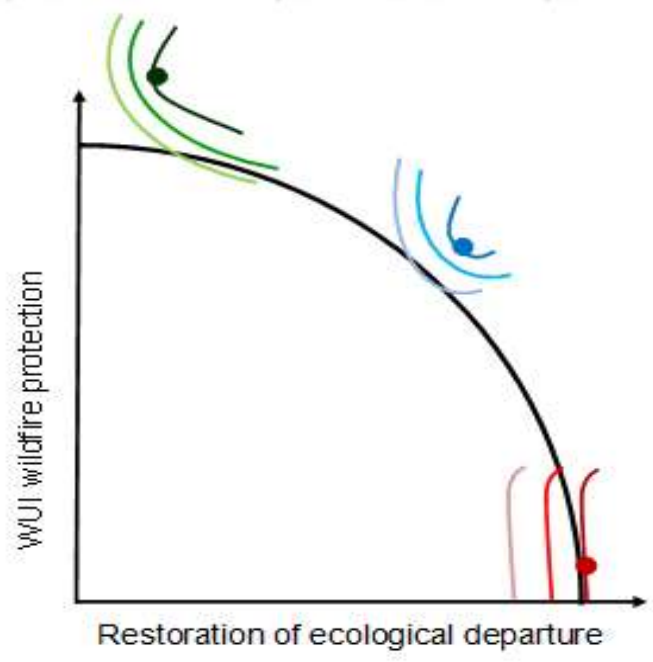

690 Fig. 11. Indifference curves superimposed on a production possibility frontier (PPF) illustrating

691 different stakeholder preferences. Indifference curves describe preferences by individual

692 stakeholders for the production of specific ecosystem services. In practice, indifference

693 relationships could be determined from preference surveys and used along with PPFs in 
694 collaborative planning to apply resource economic principles as part of the collaborative forest

695 restoration planning process. Figure adapted from King et al. (2015) for the problem of 696 restoration.

\section{Acknowledgements}

698 This work was funded by the natural resources staff group at the Pacific Northwest Region,

699 USDA Forest Service. We are grateful to Stu Brittain, Alturas Solutions, for development of the

700 Landscape Treatment Designer and to Ken Bunzel for help with GIS processing. Edwin Brown

701 and Sarah Crim provided useful guidance on several aspects of the study. We thank Rob

702 Schantz, Kone Hancock, and Neil McClusker of the Forest Service for help with parameterizing

703 the economics model. Rachel Houtman assisted with technical editing.

\section{References}

705 Adame, M., Hermoso, V., Perhans, K., Lovelock, C., Herrera-Silveira, J., 2015. Selecting cost-effective areas for restoration of ecosystem services. Conserv. Biol. 29, 493-502.

707 Agee, J.K., Skinner, C.N., 2005. Basic principles of forest fuel reduction treatments. For. Ecol. 708 Manag. 211, 83-96.

709 Ager, A.A., Day, M.A., McHugh, C.W., Short, K., Gilbertson-Day, J., Finney, M.A., Calkin, 710 D.E., 2014. Wildfire exposure and fuel management on western US national forests. J. 711 Environ. Manag. 145, 54-70.

712 Ager, A.A., Day, M.A., Vogler, K., 2016. Production possibility frontiers and socioecological tradeoffs for restoration of fire adapted forests. J. Environ. Manag. 176, 157-168.

714 Ager, A.A., Hayes, J.L., Schmitt, C.L., 2004. Simulating mortality from forest insects and 715 diseases. In: Hayes, J.L., Barbour, R.J. (Eds.), Methods for integrated modeling of 
716

717

718

719

720

721

722

723

724

725

726

727

728

729

730

731

732

733

734

735

736

737

landscape change: Interior Northwest Landscape Analysis System. Gen. Tech. Rep. PNW-GTR-610. USDA Forest Service, Pacific Northwest Research Station, Portland, OR, pp. 104-116.

Ager, A.A., McMahan, A.J., Barrett, J.J., McHugh, C.W., 2007. A simulation study of thinning and fuel treatments on a wildland-urban interface in eastern Oregon, USA. Landsc. Urban Plann. 80, 292-300.

Ager, A.A., Vaillant, N., Owens, D.E., Brittain, S., Hamann, J., 2012. Overview and example application of the Landscape Treatment Designer. Gen. Tech. Rep. PNW-GTR-859. USDA Forest Service, Pacific Northwest Research Station, Portland, OR.

Ager, A.A., Vaillant, N.M., McMahan, A., 2013. Restoration of fire in managed forests: a model to prioritize landscapes and analyze tradeoffs. Ecosphere 4(2), 29. http://dx.doi.org/10.1890/ES13-00007.1.

Allan, J.D., McIntyre, P.B., Smith, S.D.P., Halpern, B.S., Boyer, G.L., Buchsbaum, A., Burton, G.A., Jr., Campbell, L.M., Chadderton, W.L., Ciborowski, J.J.H., Doran, P.J., Eder, T., Infante, D.M., Johnson, L.B., Joseph, C.A., Marino, A.L., Prusevich, A., Read, J.G., Rose, J.B., Rutherford, E.S., Sowa, S.P., Steinman, A.D., 2013. Joint analysis of stressors and ecosystem services to enhance restoration effectiveness. Proc. Natl. Acad. Sci. 110, $372-377$.

Anderson, B.J., Armsworth, P.R., Eigenbrod, F., Thomas, C.D., Gillings, S., Heinemeyer, A., Roy, D.B., Gaston, K.J., 2009. Spatial covariance between biodiversity and other ecosystem service priorities. J. Appl. Ecol. 46, 888-896.

Bailey, D., 2013. National dialogue needed about WUI fires. Wildfire September/October, 6-7. 
738 Barbour, J., Countryman, B., Fight, R., Justice, D., McArthur, W., Powell, D., Rockwell, V.,

739 Singleton, R., Uebler, E., 2008a. Chapter 4: The quantity, composition, and economic

740 value of timber resulting from treating densely stocked stands within areas suitable for

741 sustainable harvest. Gen. Tech. Rep. PNW-GTR-752. In: Rainville, R., White, R.,

742 Barbour, J. (Eds.), Assessment of timber availability from forest restoration within the

743 Blue Mountains of Oregon. USDA Forest Service, Pacific Northwest Research Station,

744 Portland, OR, pp. 37-50.

745 Barbour, R.J., Fried, J.S., Daugherty, P.J., Christensen, G., Fight, R., 2008e. Potential biomass

746 and $\operatorname{logs}$ from fire-hazard-reduction treatments in southwest Oregon and northern

747 California. Forest Policy Econ. 10, 400-407.

748 Barbour, R.J., Hemstrom, M., Ager, A., Hayes, J.L., 2005. Effects of spatial scale on the

749 perception and assessment of risk of natural disturbance in forested ecosystems:

750 examples from northeastern Oregon. For. Ecol. Manag. 211, 210-225.

751 Beck Group, 2015. Eastern Oregon small diameter wood study. Final Project Report September

752 2015, Oregon Department of Forestry.

753 http://www.oregon.gov/ODF/Board/Documents/BOF/20160106/BOFATTCH_20160106

754 _09_01.pdf (accessed 27 July 2016).

755 BenDor, T.K., Livengood, A., Lester, T.W., Davis, A., Yonavjak, L., 2015. Defining and

756 evaluating the ecological restoration economy. Restor. Ecol. 23, 209-219.

757 Bennett, E.M., Peterson, G.D., Gordon, L.J., 2009. Understanding relationships among multiple

758 ecosystem services. Ecol. Lett. 12, 1394-1404.

759 Blignaut, J., Aronson, J., de Wit, M., 2014. The economics of restoration: looking back and

760 leaping forward. Ann. N. Y. Acad. Sci. 1322, 35-47. 
761 Brown, R.T., Agee, J.K., Franklin, J.F., 2004. Forest restoration and fire: Principles in the 762 context of place. Conserv. Biol. 18, 903-912.

763 Bullock, J.M., Aronson, J., Newton, A.C., Pywell, R.F., Rey-Benayas, J.M., 2011. Restoration of 764 ecosystem services and biodiversity: conflicts and opportunities. Trends Ecol. Evol. 26, $765 \quad 541-549$.

766 Butler, W.H., Monroe, A., McCaffrey, S., 2015. Collaborative implementation for ecological 767 restoration on US public lands: implications for legal context, accountability, and adaptive management. Environ. Manag. 55, 564-577.

769 Cattarino, L., Hermoso, V., Carwardine, J., Kennard, M.J., Linke, S., 2015. Multi-action

770 planning for threat management: A novel approach for the spatial prioritization of $771 \quad$ conservation actions. PLoS ONE 10(5), e0128027.

772 Cavender-Bares, J., Polasky, S., King, E., Balvanera, P., 2015. A sustainability framework for 773 assessing trade-offs in ecosystem services. Ecol. Soc. 20, 17.

774 Chhatre, A., Agrawal, A., 2009. Trade-offs and synergies between carbon storage and livelihood 775 benefits from forest commons. Proc. Natl. Acad. Sci. 106, 17667-17670.

776 Cochran, P.H., Geist, J.M., Clemens, D.L., Clausnitzer, R.R., Powell, D.C., 1994. Suggested 777 stocking levels for forest stands in northeastern Oregon and southeastern Washington. 778 Res. Note PNW-RN-513. USDA Forest Service, Pacific Northwest Research Station, $779 \quad$ Portland, OR.

780 Cumming, G.S., Cumming, D.H.M., Redman, C.L., 2006. Scale mismatches in social-ecological $781 \quad$ systems: causes, consequences, and solutions. Ecol. Soc. 11, 14.

782 http://www.ecologyandsociety.org/vol11/iss1/art14/. 
783 Deal, R.L., Cochran, B., LaRocco, G., 2012. Bundling of ecosystem services to increase

784 forestland value and enhance sustainable forest management. Forest Policy Econ. 17, 69-

78576.

786 Dixon, G.E., 2002. Essential FVS: A user's guide to the Forest Vegetation Simulator. Internal

787 Report. USDA Forest Service, Forest Management Service Center, Fort Collins, CO.

788 http://www.fs.fed.us/fmsc/ftp/fvs/docs/gtr/EssentialFVS.pdf (accessed 1 October 2015).

789 FHTET, 2014. 2013-2027 National Insect \& Disease Forest Risk Assessment. FHTET-14-01.

790 http://www.fs.fed.us/foresthealth/technology/nidrm2012.shtml (accessed 30 October

$7912013)$.

792 Finney, M.A., 2006. An overview of FlamMap fire modeling capabilities, in: Andrews, P.L.,

793 Butler, B.W. (Eds.), Fuels Management-How to Measure Success. Proceedings RMRS-P-

794 41. USDA Forest Service, Rocky Mountain Research Station, Portland, OR, pp. 213-220.

795 Finney, M.A., McHugh, C.W., Grenfell, I.C., Riley, K.L., Short, K.C., 2011. A simulation of

796 probabilistic wildfire risk components for the continental United States. Stoch. Env. Res.

797 Ris. A. $25,973-1000$.

798 Franklin, J.F., Hagmann, R.K., Urgenson, L.S., 2014. Interactions between societal goals and 799 restoration of dry forest landscapes in western North America. Landsc. Ecol. 29, 1645-

$800 \quad 1655$.

801 Franklin, J.F., Johnson, K.N., 2012. A restoration framework for federal forests in the Pacific Northwest. J. Forest. 110, 429-439.

803 Franklin, J.F., Johnson, K.N., Churchill, D.J., Hagmann, K., Johnson, D., Johnston, J., 2013.

804 Restoration of dry forests in eastern Oregon: a field guide. The Nature Conservancy, $805 \quad$ Portland, OR. 
806

807

808

809

810

811

812

813

814

815

816

817

818

819

820

821

822

823

824

825

826

827

828

Hagmann, R.K., Franklin, J.F., Johnson, K.N., 2013. Historical structure and composition of ponderosa pine and mixed-conifer forests in south-central Oregon. For. Ecol. Manag. 304, $492-504$.

Hartsough, B.R., Abrams, S., Barbour, R.J., Drews, E.S., McIver, J.D., Moghaddas, J.J., Schwilk, D.W., Stephens, S.L., 2008. The economics of alternative fuel reduction treatments in western United States dry forests: financial and policy implications from the National Fire and Fire Surrogate Study. Forest Policy Econ. 10, 344-354.

Hauer, G., Cumming, S., Schmiegelow, F., Adamowicz, W., Weber, M., Jagodzinski, R., 2010. Tradeoffs between forestry resource and conservation values under alternate policy regimes: A spatial analysis of the western Canadian boreal plains. Ecol. Model. 221, 2590-2603.

Haugo, R., Zanger, C., DeMeo, T., Ringo, C., Shlisky, A., Blankenship, K., Simpson, M., Mellen-McLean, K., Kertis, J., Stern, M., 2015. A new approach to evaluate forest structure restoration needs across Oregon and Washington, USA. For. Ecol. Manag. 335, $37-50$.

Haynes, R.W., Quigley, T.M., Clifford, J.L., Gravenmier, R.A., 2001. Science and ecosystem management in the interior Columbia basin. For. Ecol. Manag. 153, 3-14.

HFRA, 2003. Healthy Forest Restoration Act of 2003.

Iftekhar, M.S., Polyakov, M., Ansell, D., Gibson, F., Kay, G., 2016. How economics can further the success of ecological restoration. Conserv. Biol., n/a-n/a.

Keyser, C.E., Dixon, G.E., 2015. Blue Mountains (BM) Variant Overview - Forest Vegetation Simulator. Internal Rep. USDA Forest Service, Forest Management Service Center, Fort Collins, CO. 
829 Kimball, S., Lulow, M., Sorenson, Q., Balazs, K., Fang, Y.C., Davis, S.J., O'Connell, M.,

830 Huxman, T.E., 2015. Cost-effective ecological restoration. Restor. Ecol. 23, 800-810.

831 King, E., Cavender-Bares, J., Balvanera, P., Mwampamba, T.H., Polasky, S., 2015. Trade-offs in 832 ecosystem services and varying stakeholder preferences: evaluating conflicts, obstacles, 833 and opportunities. Ecol. Soc. 20, 25.

834 LANDFIRE, 2013a. Homepage of the LANDFIRE Project. USDA Forest Service and USDI. 835 http://www.landfire.gov/index.php (accessed 27 July 2016).

836 LANDFIRE, 2013b. LANDFIRE Vegetation Departure. US Department of Interior, Geological 837 Survey. http://www.landfire.gov/NationalProductDescriptions11.php (accessed 6 August 838 2013).

839 Larson, A.J., Churchill, D., 2012. Tree spatial patterns in fire-frequent forests of western North America, including mechanisms of pattern formation and implications for designing fuel

842 Maron, M., Cockfield, G., 2008. Managing trade-offs in landscape restoration and revegetation $843 \quad$ projects. Ecol. Appl. 18, 2041-2049.

844 Martin, D.M., Hermoso, V., Pantus, F., Olley, J., Linke, S., Poff, N.L., 2016. A proposed 845 framework to systematically design and objectively evaluate non-dominated restoration 846 tradeoffs for watershed planning and management. Ecological Economics 127, 146-155.

847 Martin, F., 2013. User Guide to the Economic Extension (ECON) of the Forest Vegetation 848 Simulator. U. S. Department of Agriculture, Forest Service, Forest Management Service 849 Center, Fort Collins, CO. 
850 Mason, C.L., Casavant, K., Lippke, B.R., Nguyen, D.K., Jessup, E., 2008. The Washington Log 851 Trucking Industry: Costs and Safety Analysis. The Rural Technology Initiative, Seattle, WA. https://www.ruraltech.org/pubs/reports/2008/log_trucks/log_truck_report.pdf.

853

854

855

856

857

858

859

860

861

862

863

864

865

866

867

868

869

870

871

872

Moore, M.M., Covington, W.W., Fule, P.Z., 1999. Historical variability concepts in ecosystem management-reference conditions and ecological restoration: a Southwestern ponderosa pine perspective. Ecol. Appl. 9, 1266-1277.

Neeson, T.M., Smith, S.D.P., Allan, J.D., McIntyre, P.B., 2016. Prioritizing ecological restoration among sites in multi-stressor landscapes. Ecol. Appl.

Noss, R.F., Franklin, J.F., Baker, W.L., Schoennagel, T., Moyle, P.B., 2006. Managing fireprone forests in the western United States. Front. Ecol. Environ. 4, 481-487.

Ohmann, J.L., Gregory, M.J., 2002. Predictive mapping of forest composition and structure with direct gradient analysis and nearest-neighbor imputation in coastal Oregon, USA. Can. J. For. Res. 32, 725-741.

Paveglio, T., Jakes, P., Carroll, M., Williams, D., 2009. Understanding social complexity within the wildland-urban interface: a new species of human habitation? Environ. Manag. 43, 1085-1095.

Payne, R.J., 2013. Human dimensions of ecological restoration: integrating science, nature and culture. Restor. Ecol. 21, 809-809.

Radeloff, V.C., Hammer, R.B., Stewart, S.I., Fried, J.S., Holcomb, S.S., McKeefry, J.F., 2005. The wildland-urban interface in the United States. Ecol. Appl. 15, 799-805.

Rainville, R., White, R., Barbour, J., 2008. Assessment of timber availability from forest restoration within the Blue Mountains of Oregon. Gen. Tech. Rep. PNW-GTR-752. USDA Forest Service, Pacific Northwest Research Station, Portland, OR. 
873 Rasmussen, M., Lord, R., Vickery, B., McKetta, C., Green, D., Green, M., Hemstrom, M.,

874 Potiowsky, T., Renfro, J., 2012. National forest health restoration: an economic

875 assessment of forest restoration on Oregon's Eastside national forests. Prepared for:

876 Governor John Kitzhaber and Oregon's Legistlative Leaders.

877 Rieman, B.E., Hessburg, P.F., Luce, C., Dare, M.R., 2010. Wildfire and management of forests

878 and native fishes: conflict or opportunity for convergent solutions? Bioscience 60, 460-

$879 \quad 468$.

880 Roccaforte, J.P., Fulé, P.Z., Covington, W.W., 2008. Landscape-scale changes in canopy fuels

881 and potential fire behaviour following ponderosa pine restoration treatments. Int. J.

$882 \quad$ Wildland Fire 17, 293-303.

883 Roesch, F.A., Reams, G.A., 1999. Analytical alternatives for an annual inventory system. J.

$884 \quad$ Forest. 97, 33-37.

885 Rollins, M.G., 2009. LANDFIRE: a nationally consistent vegetation, wildland fire, and fuel

886 assessment. Int. J. Wildland Fire 18, 235-249.

887 Rummer, B., 2008. Assessing the cost of fuel reduction treatments: a critical review. Forest

$888 \quad$ Policy Econ. 10, 355-362.

889 Schroter, M., Rusch, G.M., Barton, D.N., Blumentrath, S., Norden, B., 2014. Ecosystem services

890 and opportunity costs shift spatial priorities for conserving forest biodiversity. PLoS One

8919 9, e112557.

892 Schultz, C.A., Jedd, T., Beam, R.D., 2012. The Collaborative Forest Landscape Restoration

893 Program: a history and overview of the first projects. J. Forest. 110, 381-391. 
894 Short, K.C., 2015. Spatial wildfire occurrence data for the United States, 1992-2013

895 [FPA_FOD_20150323].3rd edition. USDA Forest Service, Rocky Mountain Research Station. http://dx.doi.org/10.2737/RDS-2013-0009.3 (accessed 27 July 2016).

897

898

899

900

901

902

903

904

905

906

907

908

909

910

911

912

913

914

915

916
Stine, P., Hessburg, P., Spies, T., Kramer, M., Fettig, C.J., Hansen, A., Lehmkuhl, J., O’Hara, K., Polivka, K., Singleton, P., Charnley, S., Merschel, A., White, R., 2014. The ecology and management of moist mixed-conifer forests in eastern Oregon and Washington: a synthesis of the relevant biophysical science and implications for future land management. Gen. Tech. Rep. PNW-GTR-897. USDA Forest Service, Pacific Northwest Research Station, Portland, OR.

Thomas, D., 2001. Managing fire in areas without roads, Fire Management Today. USDA Forest Service, Washington, DC.

USDA-USDI, 2014. The National Strategy: The final phase in the development of the National Cohesive Wildland Fire Management Strategy. http://www.forestsandrangelands.gov/index.shtml.

USDA, USDI, 1994. Record of decision for amendments to Forest Service and Bureau of Land Management Planning departments within the range of the Northern Spotted Owl. USDA Forest Service and USDI Bureau of Land Management, Portland, OR.

USDA Forest Service, 1994. Bailey's Ecoregions of the Conterminous United States. USDA Forest Service. https://www.sciencebase.gov/catalog/item/54244abde4b037b608f9e23d (accessed 10 March 2016).

USDA Forest Service, 2011. Watershed Condition Framework: A framework for assessing and tracking changes to watershed condition. FS-977. http://www.fs.fed.us/publications/watershed/. 
917 USDA Forest Service, 2012. Increasing the pace of restoration and job creation on our national

918 forests. USFS Report. United States Department of Agriculture, Forest Service,

919 Washington, D.C.

920 http://www.fs.fed.us/sites/default/files/media/types/publication/field_pdf/increasing-

921 pace-restoration-job-creation-2012.pdf (accessed 1 October 2015).

922 USDA Forest Service, 2013. Restoration of fire-dependent forests: a sense of urgency. USDA

923 Forest Service, Pacfic Northwest Region, Portland, OR.

924 http://www.fs.usda.gov/Internet/FSE_DOCUMENTS/stelprdb5423599.pdf.

925 USDA Forest Service, 2014. The rising cost of fire operations: effects on the Forest Service's

926 non-fire work. http://www.fs.fed.us/sites/default/files/media/2014/34/nr-firecostimpact-

927 082014.pdf (accessed 25 August 2014).

928 USDA Forest Service, 2015a. Collaborative Forest Landscape Restoration Program 5-Year

929 Report. FS-1047. USDA Forest Service, Washington, DC.

930 USDA Forest Service, 2016a. Blue Mountains Forest Resiliency Project: Blue Mountains

931 restoration strategy. USDA Forest Service, Ochoco, Umatilla and Wallowa Whitman

932 National Forests. http://www.fs.usda.gov/Internet/FSE_DOCUMENTS/fseprd490910.pdf

933 (accessed 9 March 2016).

934 USDA Forest Service, 2016b. Collaborative Forest Landscape Restoration Program. USDA

935 Forest Service, http://fs.fed.us/restoration/CFLRP/ (accessed 11 January 2016).

936 USDA Forest Service, Pacific Northwest Region, 2015b. Eastside restoration projects. USDA

937 Forest Service, Pacific Northwest Region.

938 http://www.fs.usda.gov/detail/r6/landmanagement/resourcemanagement/?cid=stelprdb54

93923597 (accessed 3 June 2015). 
940 Vogler, K.C., Ager, A.A., Day, M.A., Jennings, M., Bailey, J.D., 2015. Prioritization of forest

941 restoration projects: tradeoffs between wildfire protection, ecological restoration and

942 economic objectives. Forests 6, 4403-4420.

943 White, C., Halpern, B.S., Kappel, C.V., 2012. Ecosystem service tradeoff analysis reveals the 944 value of marine spatial planning for multiple ocean uses. Proc. Natl. Acad. Sci. 109, $945 \quad 4696-4701$.

946 Wilson, K.A., Lulow, M., Burger, J., McBride, M.F., 2012. The economics of restoration. In:

947 Stanturf, J., Lamb, D., Madsen, P. (Eds.), Forest Landscape Restoration. Springer, pp.

$948 \quad 215-231$.


949 Tables

950 Table 1. Delivered log values $\left(\$ \mathrm{~m}^{-3}\right)$ by species and size class used in the estimation of revenues 951 from thinning treatments.

\begin{tabular}{|c|c|c|c|c|}
\hline \multirow[b]{2}{*}{$\begin{array}{l}\text { Small-end diameter } \\
\qquad(\mathrm{cm})\end{array}$} & \multicolumn{4}{|c|}{ Species } \\
\hline & menziesii, Larix & $\begin{array}{c}\text { Tsuga spp., Abies } \\
\text { spp. }\end{array}$ & Pinus ponderosa & $\begin{array}{c}\text { Pinus contorta, } \\
\text { Picea spp. }\end{array}$ \\
\hline $12.7-20.1$ & 49.05 & 42.04 & 44.14 & 38.54 \\
\hline $20.2-30.2$ & 66.43 & 55.95 & 59.44 & 52.45 \\
\hline $30.3-45.5$ & 80.78 & 70.42 & 79.74 & 68.42 \\
\hline $45.6+$ & 98.78 & 88.90 & 119.77 & 68.42 \\
\hline
\end{tabular}

952

953 
954 Table 2. Ground-based logging activity cost $\left(\$ \mathrm{~m}^{-3}\right)$ by tree size class and number of cut trees per 955 hectare used to estimate harvesting costs for each simulated project area. Ground-based logging 956 activities were assumed in stands with an average slope $<35 \%$. Harvest cost estimates were 957 adopted from Rainville et al. (2008).

Number of cut trees per hectare

\begin{tabular}{ccccccc}
\cline { 2 - 6 } Tree size, DBH $(\mathrm{cm})$ & 12 & 49 & 124 & 247 & 494 & 988 \\
\hline $0.1-15.2$ & & & & & 37 & 34 \\
$15.3-17.8$ & & & & 30 & 28 & 26 \\
$17.9-22.9$ & & & 24 & 22 & 20 & 19 \\
$30-40.6$ & 14 & 13 & 13 & 13 & 13 \\
$40.7-53.3$ & 13 & 13 & 13 & 13 & 13 & 13 \\
\hline
\end{tabular}

958

959 
960 Table 3. Cable-based logging activity cost $\left(\$ \mathrm{~m}^{-3}\right)$ by tree size class and number of cut trees per 961 hectare for each simulated project area. Cable-based logging activities were assumed in stands

962 with an average slope $>35 \%$. Harvest cost estimates were adopted from Rainville et al. (2008).

\begin{tabular}{|c|c|c|c|c|c|c|}
\hline \multirow[b]{2}{*}{ Tree size, DBH $(\mathrm{cm})$} & \multicolumn{6}{|c|}{ Number of cut trees per hectare } \\
\hline & 12 & 49 & 124 & 247 & 494 & 988 \\
\hline $0.1-15.2$ & & & & & 130 & 91 \\
\hline $15.3-17.8$ & & & & 136 & 82 & 63 \\
\hline $17.9-22.9$ & & & 105 & 73 & 50 & 42 \\
\hline $30-40.6$ & & 30 & 29 & 26 & 26 & 25 \\
\hline $40.7-53.3$ & 25 & 21 & 20 & 20 & 20 & 20 \\
\hline
\end{tabular}

963 